School of Finance

University of St.Gallen

ECONOMETRIC ANALYSIS OF 15-MINUTE INTRADAY ELECTRICITY PRICES

RÜDIGER KIESEL

FLORENTINA PARASCHIV

WORKING PAPERS ON FiNANCE No. 2015/21

INSTITUTE OF OPERATIONS RESEARCH AND COMPUTATIONAL FINANCE (IOR/CF - HSG)

OCTOBER 2015 


\title{
Econometric analysis of 15-minute intraday electricity prices
}

\author{
Rüdiger Kiesel ${ }^{\mathrm{a}, *}$, Florentina Paraschiv ${ }^{\mathrm{b}, * *}$ \\ ${ }^{a}$ Chair for Energy Finance, University of Duisburg-Essen, Universitätsstrasse 12, \\ D-45117 Essen, Germany \\ ${ }^{b}$ Institute for Operations Research and Computational Finance, \\ University of St. Gallen, Bodanstrasse 6, CH-9000, St. Gallen, Switzerland
}

\begin{abstract}
The trading activity in the German intraday electricity market has increased significantly over the last years. This is partially due to an increasing share of renewable energy, wind and photovoltaic, which requires power generators to balance out the forecasting errors in their production. We investigate the bidding behaviour in the intraday market by looking at both last prices and continuous bidding, in the context of a fundamental model. A unique data set of 15-minute intraday prices and intraday-updated forecasts of wind and photovoltaic has been employed and price bids are modelled by prior information on fundamentals. We show that intraday prices adjust asymmetrically to both forecasting errors in renewables and to the volume of trades dependent on the threshold variable demand quote, which reflects the expected demand covered by the planned traditional capacity in the day-ahead market. The location of the threshold can be used by market participants to adjust their bids accordingly, given the latest updates in the wind and photovoltaic forecasting errors and the forecasts of the control area balances.
\end{abstract}

Keywords: intraday electricity prices, bidding behavior, renewable energy, forecasting model

*Part of the work was done while the author was visiting Center of Advanced Study, Norwegian Academy of Sciences and Letters, Oslo, as a member of the group: Stochastics for Environmental and Financial Economics

**Corresponding author: Florentina Paraschiv, florentina.paraschiv@unisg.ch; Part of the work has been done during my visiting terms at the University of Duisburg-Essen, funded by the Chair for Energy Trading and Finance. 

closure of the day-ahead market. Exchange (EPEX).

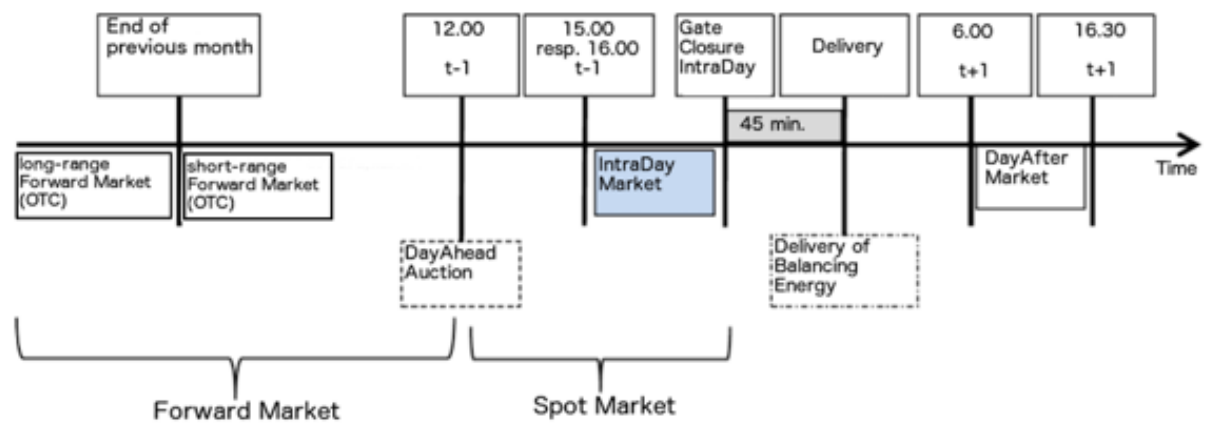

Figure 1: Timing Electricity Trading

\section{Introduction}

Trading in the intraday electricity markets increased rapidly since the opening of the market. This may be driven by the need of photovoltaic and wind power operators to balance their production forecast errors, i.e. deviations between forecasted and actual production. Evidence for this is a jump in the volume of intraday trading as the direct marketing of renewable energy was introduced. Furthermore, there may be a generally increased interest in intraday trading activities due to proprietary trading. We study the structure of intraday trading of electricity and identify the price-driving factors. Our main goal is to identify market fundamental factors that influence the bidding behavior in the 15-minute intraday market at European Power

Along the basic timeline of electricity trading activities, see Figure 1, the intraday activities relate mostly to further adjustments of positions after the

While day-ahead trading offers the possibility to correct long-term production schedule (build on the forward markets) in terms of hourly production schedule of power plants (Delta Hedging) and to adjust for residual load profiles on an hourly basis, the increasing share of renewable energy sources (wind, solar) in electricity markets requires a finer adjustment.

According to the Equalization Mechanism Ordinance (ger.: Verordnung zur Weiterentwicklung des bundesweiten Ausgleichsmechanismus, abbr.: 
AuglMechV) all electricity generated by renewable sources has to be traded day-ahead. This is usually done by the transmission system operator (TSO) with the plant operator receiving a legally guaranteed feed-in-tariff. From 2012 on the inclusion of a market premium led direct marketers within the feed-in premium support scheme to enter the market as well. Trading of electricity from a renewable energy source is based on forecasts which may have a horizon of up to $36 \mathrm{~h}$ (taking some data-handling into account). To correct errors in forecasts the AusglMechV requires the marketers of renewable energy to use the intraday market to balance differences in actual and updated forecasts. Intraday trading starts at $3 \mathrm{pm}$ and takes place continuously until up to $45 \mathrm{~min}$ (by 2015 this was shortened to $30 \mathrm{~min}$ ) before the start of the traded quarter-hour. As forecasts change regularly, marketers may sell and buy the same contract at different times during the trading period.

After the closure of the intraday market balancing energy has to be used to close differences between available and forecasted electricity. As a smaller number of power plants are used for balancing energy the merit-order curve is steeper than that in the intraday market. Thus on average larger prices are paid and marketers aim at minimising this difference, see [5]. In addition, TSOs may impose sanctions on marketers who frequently require balancing energy.

Balancing energy is supplied by generators with the necessary flexibility to balance the market. In case generation is below demand positive balancing energy is used, otherwise negative balancing energy. [6] and [13] contain a detailed description of the integration of renewable energy in electricity markets and the regulatory requirements and we refer the reader to these sources for further information.

The day-ahead market (spot market) and the balancing markets have been investigated extensively. For example, ([22]) show that the day-ahead price formation process at EPEX depends on the interaction/substitution effect between the traditional production capacity (coal, gas, oil) with the fluctuant renewable energies (wind and photovoltaic (PV)). Further empirical studies on intraday/balancing markets include [1], [16]. Also, [18] studies strategic behaviour linking day-ahead and balancing markets.

An investigation in the merit-order effect is given by [2], wo find that electricity generation by wind and PV has reduced spot market prices considerably by $6 € / \mathrm{MWh}$ in 2010 rising to $10 € / \mathrm{MWh}$ in 2012 . They also show that merit order effects are projected to reach 14-16 €/MWh in 2016.

Recent studies of the intraday high-frequency electricity prices at EPEX 
are [8] and [9] who look at liquidity effects and forecast determinants on a hourly basis. Also, [3] considers trading strategies to minimise costs from imbalances for both PV and wind, but generates price changes in terms of a reduced-form model (using a stochastic process). The focus lies in developing a trading strategy for a given setting, and not on explaining the relevant price process. Several studies have discussed the effects of prognosis errors for wind generation (see [15] and [20]). As Figure 2 suggests a PV production introduces quarter-hour ramps quite naturally. In addition, changes in forecasts of renewable energy production require a timely correction of day-ahead positions. However, photovoltaic has not been investigated so far.

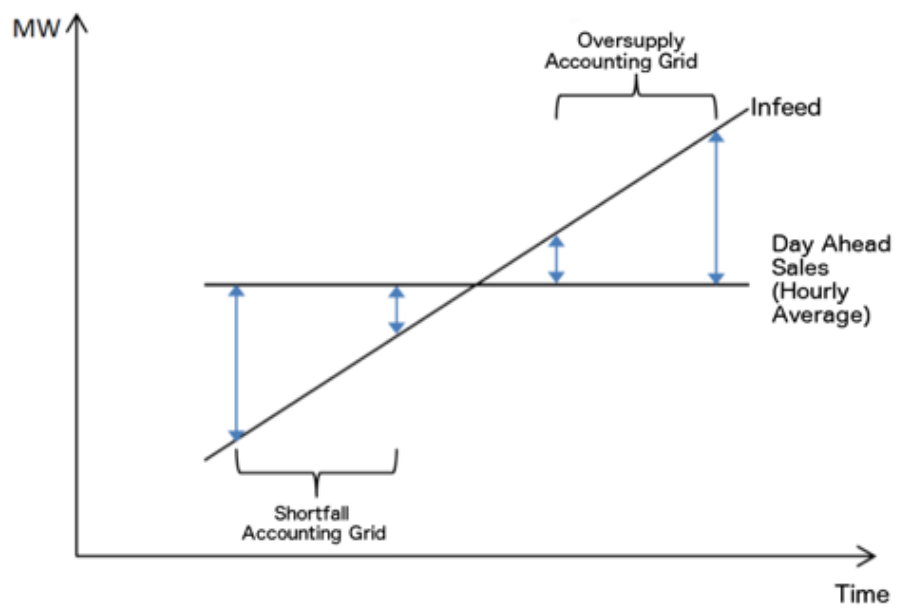

Figure 2: Quarter Hour Ramps

[8] and [9] used the ex-post published wind infeed data to explain ex-ante their impact on the day-ahead market. These are publicly available data from the Transparency Platform EPEX. However, the actual infeed is only known ex-post and therefore it cannot be used directly to explain the price formation on the intraday market. In fact, the intraday market participants have access to updated forecasts of wind. In our study, we will extend the existing literature by taking into account the intraday updated forecasts for wind and PV, which have been supplied by EWE Trading GmbH.

Each day, hourly day-ahead electricity prices are revealed around $2 \mathrm{pm}$ at EPEX (see [23]). At the same time, market participants have access to forecasts for wind and PV published by each Transmission System Operator (TSO) in 15-minute intervals for the next day. However, wind and PV fore- 
casts are updated frequently during the trading period. Thus, at the time when market participants place their bids for a particular intraday delivery period (hour, quarter of hour), updated information about the forecasting errors of renewables becomes available. In consequence, also deviations between the intraday prices and the day-ahead price for a specific hour are expected to occur. Our main research question is, thus, to which extent do market participants change their bidding behavior when new information on wind and PV forecasts becomes available. We will employ a unique data set of the latest forecasts of wind and PV available at the time of the bid.

Our analysis is twofold: Firstly, we derive an asymmetric fundamental model for the difference between the last price bid for a certain quarter of hour and the day-ahead price for that hour. We distinguish between summer/winter, peak/off-peak hours. We test for asymmetric behavior of prices to forecasting errors of renewable energy dependent on the demand quote regime and further investigate the typical jigsaw pattern of intraday prices. Thus, we identify a seasonality shape that provides traders important information about the time of the day when they can bid, dependent on their demand/supply profiles. Furthermore, the effect of volume of trades/market liquidity are investigated. Secondly, we are interested in the bidding behavior of market participants in the intraday electricity market, continuous bidding. We thus analyse the continuous trades and disentangle the effect of market fundamentals dependent on the time of the day. The econometric model is replicated for several traded hourly quarters, in different time of the day. In particular, we are interested to see how delta bid prices change when new information becomes available in the intraday renewable forecasts for wind and PV. We look at the trade-off between autoregressive terms and fundamental factors impacting the intraday price formation process.

Our contribution to the existing literature is twofold: we use ex-ante forecasts of fundamental variables and employ high-frequency, namely quarterhourly intraday prices.

\section{Model architecture}

Our main assumption is that the electricity intraday price formation process depends on how much traditional capacity has been allocated in the day-ahead market and in which proportion it covers the forecasted demand. Let us consider two possible market regimes: 
1. The traditional capacity planned for the day-ahead satisfies the expected demand for a certain hour;

2. There is a certain demand quote uncovered by the planned capacity.

Thus, in scenario 2, negative forecasting errors of wind and PV will increase faster the intraday prices than in scenario 1 , due to the excess demand pressure. Viceversa, in scenario 1, positive forecasting errors in renewables will put pressure on traditional suppliers to reduce the production, since renewables are fed into the grid with priority (on average $20 \%$ of electricity production in Germany is wind and PV based). Thus, prices will decrease faster than in scenario 2, where the excess of renewables (positive updated forecasts) will balance out the excess demand. Therefore, in the context of a threshold model, we investigate whether there is an asymmetric adjustment of the intraday prices to forecasting errors in renewables, dependent on the demand quote regime (proportion of the forecasted demand for electricity in the planned traditional capacity for the day-ahead). The location of the threshold in the demand quote is estimated and this gives an indication of the bidding behavior in the intraday market. Market participants can compare the identified threshold value to the forecasted demand quote for a certain hour to identify the market regime and to further define a bidding strategy. Employing the demand quote as threshold variable is supported by the literature as several papers have found that total electricity demand influences price behaviour strongly. In [14] it is shown that the ratio between wind and conventional power production affects the electricity price most (the so-called wind penetration). [19] identify the residual load, the electricity demand that needs to be met by conventional power, as an important variable.

To include trading volume as a fundamental variable is also supported by the literature as e.g. [6] find that the forecast balancing costs in intraday trading are linked to the trading volume. This is in line with earlier papers, such as [17] and [4], who estimate asymmetric GARCH models and include traded electricity volume in the variance equation to study its impact on price volatility.

In a first part of our analysis we aim at a model for the difference between the last intraday bid price for a certain quarter of an hour and the day-ahead price for that specific hour. As a prerequisite for our modeling approach, we investigate the typical jigsaw pattern of the 15-minute intraday prices and control for seasonality. Figures 3, 4, 5 show the long-term mean of last prices 
and average prices bid for a certain quarter of an hour between 01/01/201401/07/2014. During the day, the jigsaw pattern is mainly explained by the following situation: Renewable energy providers sell day-ahead the full hour (average of all quarters). During morning (evening) hours the sun goes up (down) so in the first quarter there is a buy-pressure on them as they are not able to produce the hourly average. On the other hand, in the fourth quarter they produce too much and have to sell.

We also found a persistent jigsaw pattern of prices during off-peak hours. This is driven by the production design of fossil power plants (supply side: when it starts low and ends high) or power-intensive industry (demand side: when it starts high and ends low).

A reason for that my be inter-temporal restrictions in using fossil plants. In addition to fuel costs, these plants have ramp-up and ramp-down costs, which prevent plant operators from shutting down plants in case of drops in demand or starting up plants in case of spikes in demand. The short-term marginal costs from this may dominate fuel costs.

\section{Data}

As motivated in section 2, for the analysis we employed historical dayahead and intraday electricity prices for 15-minute products in the continuous trading system between 01/01/2014-30/06/2014. As fundamental variables selected in this study we refer to demand forecast, power plant availability, intraday updated forecasts for wind and photovoltaic, volume trades in the continuous trading, and the control area balance. The latter represents the corresponding use of balancing power in the balancing market ${ }^{1}$. In particular, the control area balance corresponds to the sum of all balance group deviations of balance groups registered at the transmission system operator and of the relevant balance groups owned by the transmission system operator (e.g. EEG, grid losses, unintentional deviation) ${ }^{2}$. In Tables 1 and 2 we give an overview of the data sources and their frequency, respectively.

\footnotetext{
${ }^{1}$ As balance group deviations are not immediately available online the control area balance is calculated on the basis of the corresponding use of balancing power. The published data are values from operating measurements that are adjusted by measurement corrections if necessary. The actual settlement-relevant data can be retrieved under the prices for grid balancing.

${ }^{2}$ see http://www.tennettso.de
} 


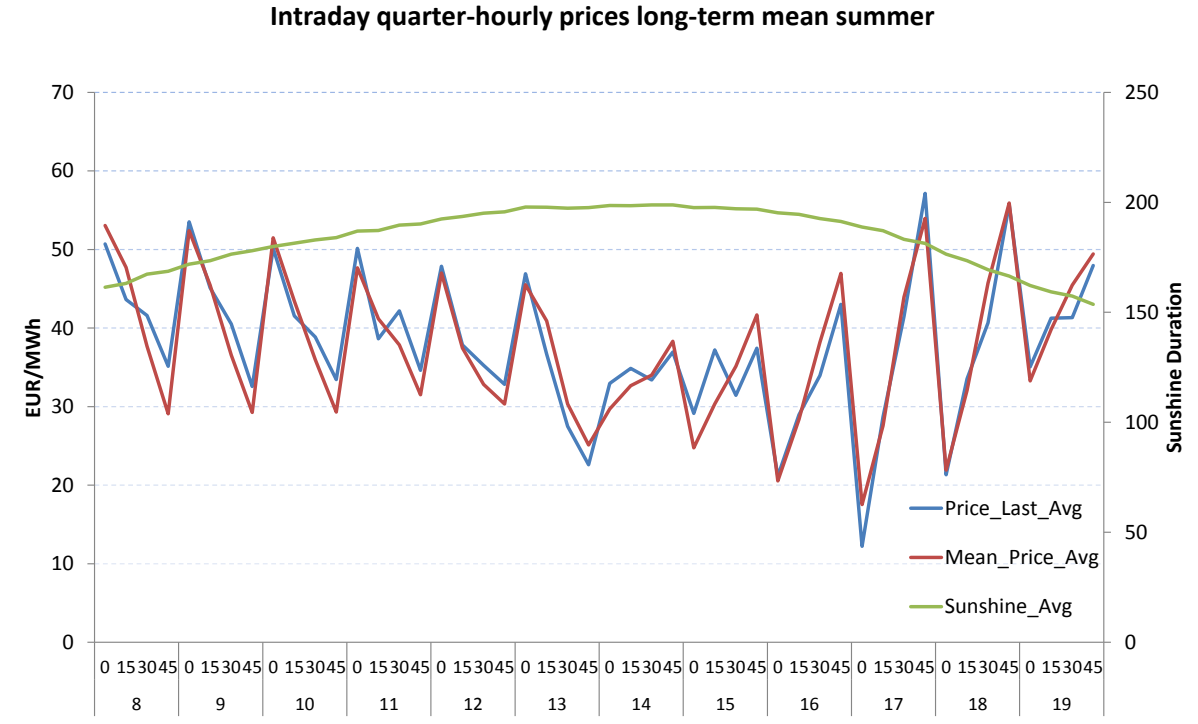

Intraday quarter-hourly prices long-term mean summer

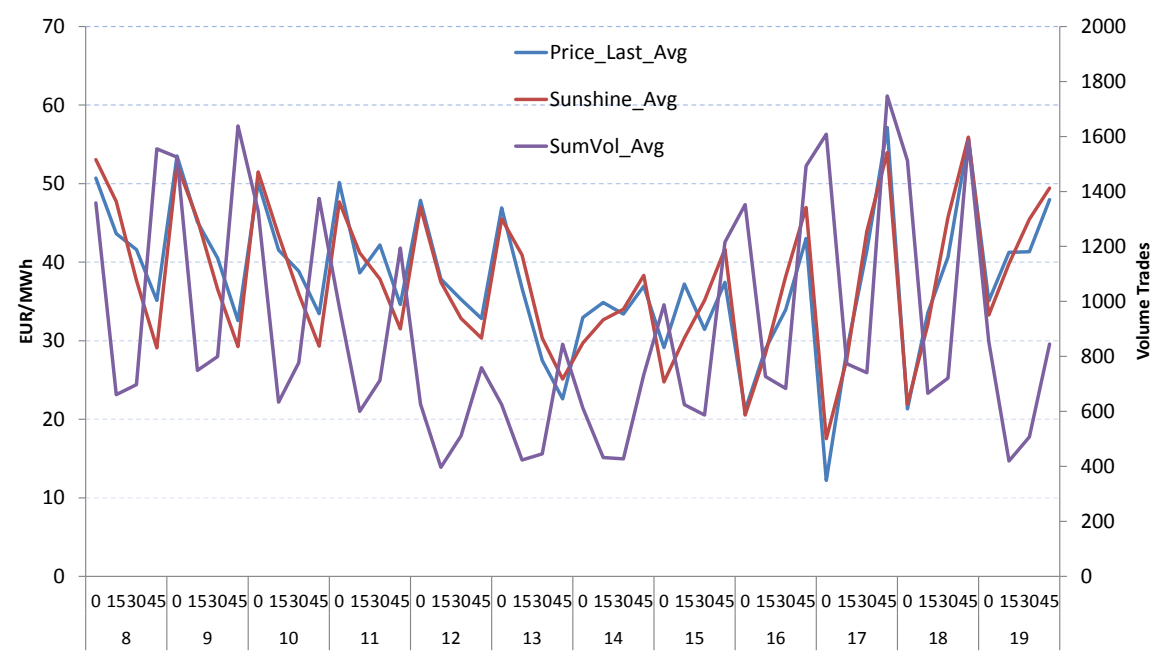

Figure 3: Seasonality pattern of the last prices and average prices bid for a certain quarter of an hour during the peak hours in summer. The right axes show the sunshine duration and the sum of volumes traded. 

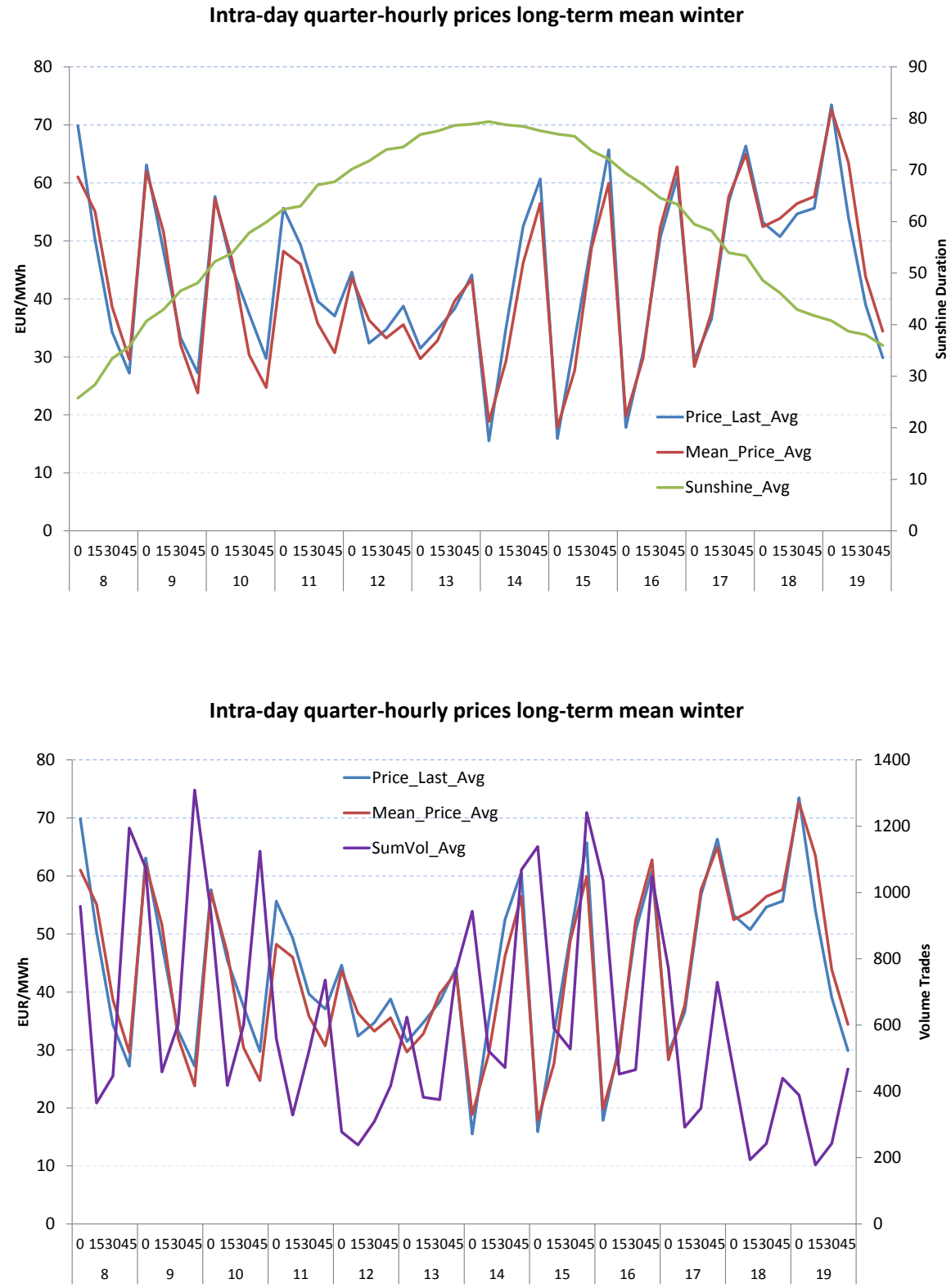

Figure 4: Seasonality pattern of the last prices and average prices bid for a certain quarter of an hour during the peak hours in winter. The right axes show the sunshine duration and the sum of volumes traded. 

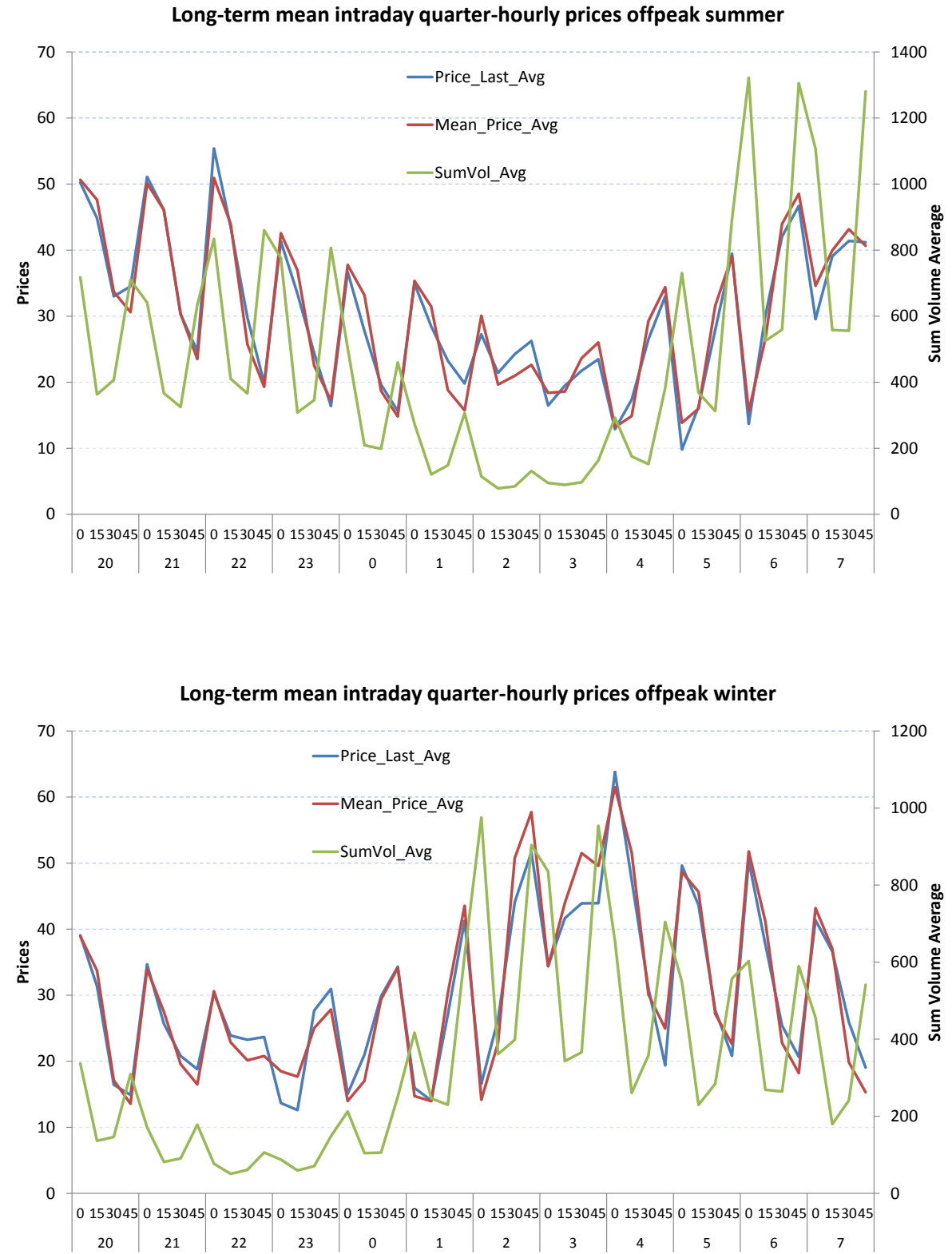

Figure 5: Seasonality pattern of the last prices and average prices bid for a certain quarter of an hour during the off-peak hours in summer and winter, respectively. The right axis shows the sum of volumes traded. 


\begin{tabular}{|c|c|c|}
\hline $\begin{array}{l}\text { Variable } \\
\text { units }\end{array}$ & Description & Data Source \\
\hline $\begin{array}{l}\text { Day-ahead Price } \\
\text { EUR/MWh }\end{array}$ & $\begin{array}{l}\text { Market clearing price for a cer- } \\
\text { tain hour in the day-ahead auc- } \\
\text { tions (Phelix) }\end{array}$ & $\begin{array}{l}\text { European Power Exchange (EPEX) } \\
\text { https://www.epexspot.com/en/ }\end{array}$ \\
\hline $\begin{array}{l}\text { Intraday Price } \\
\text { EUR/MWh }\end{array}$ & $\begin{array}{l}\text { Intraday electricity prices for } \\
15 \text {-minute products in the con- } \\
\text { tinuous trading }\end{array}$ & $\begin{array}{l}\text { European Energy Exchange Trans- } \\
\text { parency Platform: } \\
\text { http://www . eex-transparency .com/de }\end{array}$ \\
\hline $\begin{array}{l}\text { Intraday Volume } \\
\text { Trades } \\
\text { MWh }\end{array}$ & $\begin{array}{l}\text { Intraday volume trades for } 15- \\
\text { minute products in the contin- } \\
\text { uous trading }\end{array}$ & $\begin{array}{l}\text { European Energy Exchange Trans- } \\
\text { parency Platform: } \\
\text { http://www.eex-transparency.com/de }\end{array}$ \\
\hline $\begin{array}{l}\text { Wind Forecast } \\
\text { MW }\end{array}$ & $\begin{array}{l}\text { Sum of intraday forecasted in- } \\
\text { feed of wind electricity into the } \\
\text { grid }\end{array}$ & $\begin{array}{l}\text { EWE TRADING GmbH } \\
\text { http://www.ewe.com/en/ }\end{array}$ \\
\hline $\begin{array}{l}\text { PV Forecast } \\
\text { MW }\end{array}$ & $\begin{array}{l}\text { Sum of intraday forecasted in- } \\
\text { feed of PV electricity into the } \\
\text { grid }\end{array}$ & $\begin{array}{l}\text { EWE TRADING GmbH } \\
\text { http://www.ewe.com/en/ }\end{array}$ \\
\hline $\begin{array}{l}\text { Expected Power } \\
\text { Plant Availability } \\
\text { MW }\end{array}$ & $\begin{array}{l}\text { Ex-ante expected power plant } \\
\text { availability for electricity pro- } \\
\text { duction on the delivery day } \\
\text { (daily granularity), daily pub- } \\
\text { lished at } 10: 00 \text { am }\end{array}$ & $\begin{array}{l}\text { European Energy Exchange } \\
\text { \& transmission system operators: } \\
\text { ftp://infoproducts.eex.com }\end{array}$ \\
\hline $\begin{array}{l}\text { Expected Demand } \\
\text { MW }\end{array}$ & $\begin{array}{l}\text { Demand forecast for the rele- } \\
\text { vant hour on the delivery day }\end{array}$ & $\begin{array}{l}\text { European Network of Transmission } \\
\text { System Operators (ENTSOE): } \\
\text { https://transparency.entsoe.eu/ }\end{array}$ \\
\hline $\begin{array}{l}\text { Control area bal- } \\
\text { ance } \\
\text { MW }\end{array}$ & $\begin{array}{l}\text { Balancing market margins, } \\
\text { available ex-post for a certain } \\
\text { delivery period }\end{array}$ & $\begin{array}{l}\text { Transmission system operators: } \\
\text { http: //www.50Hertz.com, } \\
\text { http://www.amprion.de, } \\
\text { http: //www.transnetbw.de, } \\
\text { http://www.tennettso.de }\end{array}$ \\
\hline
\end{tabular}

Table 1: Overview of fundamental variables used in the analysis

\begin{tabular}{|c|c|c|c|}
\hline Variable & Daily & Hourly & quarter-hourly \\
\hline Day-ahead Price & & $x$ & \\
\hline Intraday Price & & & X \\
\hline Intraday Volume Trades & & & X \\
\hline Wind Forecast & & & X \\
\hline PV Forecast & & & X \\
\hline Expected Power Plant Availability & X & & \\
\hline Expected Demand & & $x$ & \\
\hline Control area balance & & & X \\
\hline
\end{tabular}

Table 2: Data granularity of fundamental variables

\section{Methodology}

\subsection{Threshold model specification}

The technical specification of our model follows [21] and reads:

$$
y_{i}=\theta_{1}^{\prime} x_{i}+\varepsilon_{i}, \quad \omega_{i} \leq \tau,
$$




$$
y_{i}=\theta_{2}^{\prime} x_{i}+\varepsilon_{i}, \quad \omega_{i}>\tau,
$$

where $\omega_{i}$ is the threshold variable used to split the sample into two regimes. The random variable $\varepsilon_{i}$ is a regression error.

Our observed sample is $\left\{y_{i}, x_{i}, \omega_{i}\right\}_{i=1}^{n}$, where $y_{i}$ represent the dependent variable and $x_{i}$ is an $m$-vector of independent variables. The threshold variable $\omega_{i}$ may be an element of $x_{i}$ and is assumed to have a continuous distribution. To write the model in a single equation ${ }^{3}$, we define the dummy variable $d_{i}(\tau)=\mathbf{1}\left[\omega_{i} \leq \tau\right]$, where $\mathbf{1}[\cdot]$ is the indicator function and we set $x_{i}(\tau):=x_{i} d_{i}(\tau)$. Furthermore, let $\lambda_{n}^{\prime}=\theta_{2}^{\prime}-\theta_{1}^{\prime}$ denote the threshold effect. Thus, equations (1) and (2) become:

$$
y_{i}=\theta^{\prime} x_{i}+\lambda_{n}^{\prime} x_{i}(\tau)+\varepsilon_{i}
$$

In order to simplify the threshold estimation procedure, we rewrite equation (3) in matrix notation. We define the vectors $Y \in \mathbb{R}^{n}$ and $\varepsilon \in \mathbb{R}^{n}$ by stacking the variables $y_{i}$ and $\varepsilon_{i}$, and the $n \times m$ matrixes $X \in \mathbb{R}^{n \times m}$ and $X(\tau) \in \mathbb{R}^{n \times m}$ by stacking the vectors $x_{i}^{\prime}$ and $x_{i}(\tau)^{\prime}$. Then (3) can be written as:

$$
Y=X \theta+X(\tau) \lambda_{n}+\varepsilon
$$

The regression parameters are $\left(\theta, \lambda_{n}, \tau\right)$ and the natural estimator is least squares (LS).

\subsection{Hansen's grid search to locate the most likely threshold}

To determine the location of the most likely threshold, we will apply Hansen's grid search. In the implementation of this threshold estimation procedure, we follow [11] and [12]. This paper develops a statistical theory for threshold estimation in the regression context. As mentioned in the previous section, the regression parameters are $\left(\theta, \lambda_{n}, \tau\right)$. Let

$$
S_{n}(\theta, \lambda, \tau)=(Y-X \theta-X(\tau) \lambda)^{\prime}(Y-X \theta-X(\tau) \lambda)
$$

be the sum of squared errors function. Then, by definition, the LS estimators $\hat{\theta}, \hat{\lambda}, \hat{\tau}$ jointly minimize (5). For this minimization, $\tau$ is assumed to be restricted to a bounded set $[\underline{\tau}, \bar{\tau}]=\Omega$. The LS estimator is also the MLE

\footnotetext{
${ }^{3}$ see Hansen (2000)
} 
when $\varepsilon_{i}$ is i.i.d. $N\left(0, \sigma^{2}\right)$. Following [11], the computationally easiest method to obtain the LS estimates is through concentration. Conditional on $\tau$, equation (4) is linear in $\theta$ and in $\lambda_{n}$, yielding the conditional OLS estimators $\hat{\theta}(\tau)$ and $\hat{\lambda}(\tau)$ by regression of $Y$ on $X(\tau)^{*}=[X X(\tau)]$. The concentrated sum of squared errors function is

$$
S_{n}(\tau)=S_{n}(\hat{\theta}(\tau), \hat{\lambda}(\tau), \tau)=Y^{\prime} Y-Y^{\prime} X(\tau)^{*}\left(X(\tau)^{*^{\prime}} X(\tau)^{*}\right)^{-1} X(\tau)^{*^{\prime}} Y,
$$

and $\hat{\tau}$ is the value that minimizes $S_{n}(\tau)$, i.e.,

$$
\hat{\tau}=\operatorname{argmin} S_{n}(\tau)
$$

To test the hypothesis $H_{0}: \tau=\tau_{0}$, a standard approach is to use the likelihood ratio statistic under the auxiliary assumption that $\varepsilon_{i}$ is i.i.d. $N\left(0, \sigma^{2}\right)$.

Let

$$
L R_{n}(\tau):=n \frac{S_{n}(\tau)-S_{n}(\hat{\tau})}{S_{n}(\hat{\tau})} .
$$

The likelihood ratio test of $H_{0}$ is to reject for large values of $L R_{n}\left(\tau_{0}\right)$. Using the $L R_{n}(\tau)$ function, asymptotic $p$-values for the likelihood ratio test are derived:

$$
p_{n}=1-\left(1-\exp \left(-1 / 2 \cdot L R_{n}\left(\tau_{0}\right)^{2}\right)\right)^{2} .
$$

\section{Fundamental modeling of intraday prices}

We examine whether deviations between the intraday and day-ahead prices for a certain quarter of a hourly delivery period are caused by market fundamentals. Deviations between the intraday and the day-ahead prices are caused by the fluctuant renewable energy which must be fed into the grid with priority. Thus, at the time when market participants place their bids for a certain delivery period intraday, they update their information about the forecasted wind and PV for the relevant quarter of an hour. Wind and PV power operators must balance out their production forecast errors and deviations from the day-ahead price are expected to occur. Forecasting errors of renewables are thus expected to cause deviations between the intraday and day-ahead prices. Their impact on prices, however, should not be judged in isolation, but dependent on the demand quote, meaning the extent at which forecasted demand for a certain hour is covered by the traditional capacity planned in the day-ahead market. 
As discussed in section 2, dependent on the demand quote regime, thus, if there is excess demand or not in the market, positive and negative forecasting errors in wind and PV are expected to have different impact on price deviations. In the context of a threshold model specification, where the threshold variable is the demand quote, we will examine these dynamics.

\subsection{Modeling deviations of last prices from the day-ahead price}

In the first part of our analysis, we analyze the differences between the historical last prices bid for a certain 15-minute delivery period in the intraday market and the day-ahead price for the corresponding hour. We used historical last prices sorted for quarter-hourly products between 01/01/201430/06/2014. As market fundamentals we include positive/negative forecasting errors in wind and PV, defined as deviations between the latest forecast available at the time when the last prices are observed and the day-ahead available forecasts. The last prices for a certain delivery period are placed in the market not later than 30 minutes before the delivery period starts ${ }^{4}$. At this time, market participants can also forecast the volume in the balancing market, namely positions that could not be filled in the intra-day market. These positions are defined by the Transmission System Operators as "control area balances" 5 .

We derive the forecasts of the control area balance on an autoregressive model. ${ }^{6}$ Historical control area balances are therefore modeled by an autoregressive model, as shown in Table 3. The order of lags has been identified by examining the autocorrelation function and we further performed Akaike (AIC) and Bayesian (BIC) information criteria to select the best model ${ }^{7}$. We found that the control area balances for a certain 15-minute delivery period can be forecasted based on the last 8 observations (up to 2 hours ago). Forecasts based on this model are further included in our model estimation.

The demand quote is defined as:

$$
\text { DemandQuote }_{t}=\text { DemandForecast }_{t} / P P A_{d t}
$$

where $d$ is the day-ahead and $t$ one hour in day $d$.

\footnotetext{
${ }^{4}$ Since 16th July, 2015, EPEX Spot will shorten the lead time from 45- to 30 minute before delivery (see European Power Exchange (EPEX) https://www . epexspot.com/en/).

${ }^{5}$ see http://www.tennettso.de

${ }^{6}$ Discussions with traders revealed that this is a common praxis in the industry.

${ }^{7}$ Results are available upon request
} 
Table 3: Autoregressive model for control area balances

\begin{tabular}{lrrrr}
\hline \hline \multicolumn{4}{l}{ Dependent Variable: Balances } \\
Method: Least Squares \\
Included observations: 2535 after adjustments \\
\hline Variable & Coefficient & Std. Error & t-Statistic & Prob. \\
\hline C & $18.551^{*}$ & 6.228 & 2.978 & 0.002 \\
Balances(-1) & 0.818 & 0.019 & 41.195 & 0 \\
Balances(-2) & 0.055 & 0.025 & 2.160 & 0.031 \\
Balances(-3) & -0.072 & 0.025 & -2.809 & 0.005 \\
Balances(-4) & 0.162 & 0.025 & 6.359 & 0 \\
Balances(-5) & -0.132 & 0.025 & -5.166 & 0 \\
Balances(-6) & -0.013 & 0.025 & -0.543 & 0.586 \\
Balances(-7) & -0.004 & 0.025 & -0.185 & 0.852 \\
Balances(-8) & 0.047 & 0.019 & 2.369 & 0.017 \\
\hline R-squared & 0.727 & Mean dependent var & 131.686 \\
Adjusted R-squared & 0.726 & S.D. dependent var & 577.588 \\
S.E. of regression & 301.8479 & Akaike info criterion & 14.261 \\
Sum squared resid & $2.30 \mathrm{E}+08$ & Schwarz criterion & 14.281 \\
Log likelihood & -18067.2 & Hannan-Quinn criter. & 14.268 \\
F-statistic & 844.035 & Durbin-Watson stat & 1.998 \\
Prob(F-statistic) & 0 & & \\
\hline \hline
\end{tabular}

The order of lags has been identified by examining the autocorrelation function and we further performed Akaike (AIC)and Bayesian (BIC) information criteria to select the best model. 
In Tables 4 and 5 we show descriptive statistics of the selected input variables. We distinguish between summer/winter, peak/off peak hours (as shown in [23]). We observe that, independent on the season, on average the intraday last price for 15-minute delivery periods is below the day-ahead price for the corresponding hour. Furthermore, the difference becomes larger and more volatile for off-peak than for peak hours and in winter than in summer. The control area balances are, on average, negative in winter and turn into positive in summer.

On average, the demand quote is higher and more volatile during peak than in off-peak hours, which makes the planning of traditional capacity for the day ahead more difficult.

To test for stationarity we perform an augmented Dickey-Fuller test (ADF test). For all variables we reject the null hypothesis of a unit root at a $95 \%$ significance level meaning that the data is stationary.

As shown in Figures 3 and 4, there is a clear jigsaw seasonality in the last prices, independent on the season. Based on the information of the longterm dynamics of historical last prices, we control for the seasonal pattern by introducing dummy variables as follows:

\section{- Summer peak}

- We introduce one Dummy variable for each of the Q1-Q4 quarters for the interval 08:00-13:00 (Morning pattern)

- We introduce one Dummy variable for each of the Q1-Q4 quarters for the interval 14:00-18:00 (Afternoon pattern)

\section{- Winter peak}

- We introduce one Dummy variable for each of the Q1-Q4 quarters for the interval 08:00-12:00 (Morning pattern)

- We introduce one Dummy variable for each of the Q1-Q4 quarters for the interval 13:00-17:00 (Afternoon pattern)

\section{- Summer off-peak}

- We introduce one Dummy variable for each of the Q1-Q4 quarters for the interval 20:00-01:00 (Evening descending pattern)

- We introduce one Dummy variable for each of the Q1-Q4 quarters for the interval 03:00-07:00 (Early morning ascending pattern) 


\section{- Winter off-peak}

- We introduce one Dummy variable for each of the Q1-Q4 quarters for the interval 20:00-21:00 and 04:00-07:00 (Descending pattern)

- We introduce one Dummy variable for each of the Q1-Q4 quarters for the interval 23:00-03:00 (Night, ascending pattern)

The model specification reads:

$$
\begin{aligned}
& \left(P_{t}^{I D}-P_{t}^{\text {Dahd }}\right)^{h}=c^{h}+\beta^{h} \text { ControlAreaBalance } \mathbf{1}_{t}^{h}+\theta^{h} \text { DemandQuote }_{t} \mathbf{1}_{t}^{h} \\
& +k^{h n}\left(\text { Wind }_{t}^{I D}-\text { Wind }{ }_{t}^{\text {Dahd }}\right) \mathbf{1}_{t}^{h} \mathbf{1}_{t}^{n}+k^{h p}\left(\text { Wind }_{t}^{I D}-\right. \\
& \left.-W i n d_{t}^{D a h d}\right) \mathbf{1}_{t}^{h} \mathbf{1}_{t}^{p}+k^{h n}\left(P V_{t}^{I D}-P V_{t}^{\text {Dahd }}\right) \mathbf{1}_{t}^{h} \mathbf{1}_{t}^{n} \\
& +k^{h p}\left(P V_{t}^{I D}-P V_{t}^{\text {Dahd }}\right) \mathbf{1}_{t}^{h} \mathbf{1}_{t}^{p}+\sum_{j=1}^{8} \delta_{j}^{h} D Q_{j} \\
& \left(P_{t}^{I D}-P_{t}^{\text {Dahd }}\right)^{l}=c^{l}+\beta^{l} \text { ControlAreaBalance } \mathbf{1}_{t}^{l}+\theta^{l} \text { DemandQuote }_{t} \mathbf{1}_{t}^{l} \\
& +k^{l n}\left(W_{i n d}^{I D}-W i n d_{t}^{D a h d}\right) \mathbf{1}_{t}^{l} \mathbf{1}_{t}^{n}+k^{l p}\left(W_{i n d}^{I D}-\right. \\
& \left.- \text { Wind }_{t}^{\text {Dahd }}\right) \mathbf{1}_{t}^{l} \mathbf{1}_{t}^{p}+k^{l n}\left(P V_{t}^{I D}-P V_{t}^{\text {Dahd }}\right) \mathbf{1}_{t}^{l} \mathbf{1}_{t}^{n} \\
& +k^{l p}\left(P V_{t}^{I D}-P V_{t}^{D a h d}\right) \mathbf{1}_{t}^{l} \mathbf{1}_{t}^{p}+\sum_{j=1}^{8} \delta_{j}^{l} D Q_{j}
\end{aligned}
$$

As threshold variable, the demand quote splits the data in two regimes: high/sufficient demand quote ("h") or low ("1"). The indicator function $\mathbf{1}_{t}^{p / n}$ further distinguishes in each regime between positive/negative forecasting errors in the renewables.

\subsection{Model for the continuous trades for quarter-hourly products}

In the second part, we examine the continuous trades for several quarterhourly products. Thus, we are interested to see how delta bid prices change when new information on wind and PV for a certain delivery period of interest becomes available intraday. We are interested in the bidding behavior of market participants in the intraday electricity market as influenced by 
market fundamentals. In particular, we are interested to see how delta bid prices for a certain quarter of an hour change when new information on the forecasts for wind and PV becomes available. We look at the trade-off between autoregressive terms and fundamental factors impacting the intraday price formation process.

The model specification reads:

$$
\begin{aligned}
\left(\Delta P_{t}^{I D}\right)^{h} & =c^{h}+\alpha_{1}^{h} \Delta P_{t-1}^{I D} \mathbf{1}_{t}^{h}+\alpha_{2}^{h} \Delta P_{t-2}^{I D} \mathbf{1}_{t}^{h}+\alpha_{3}^{h} \Delta P_{t-3}^{I D} \mathbf{1}_{t}^{h} \\
& +k_{w}^{h n}\left(\Delta W i n d_{t}^{I D}\right) \mathbf{1}_{t}^{h} \mathbf{1}_{t}^{n}+k_{w}^{h p}\left(\Delta W i n d_{t}^{I D}\right) \mathbf{1}_{t}^{h} \mathbf{1}_{t}^{p} \\
& +k_{P V}^{h n}\left(\Delta P V_{t}^{I D}\right) \mathbf{1}_{t}^{h} \mathbf{1}_{t}^{n}+k_{P V}^{h p}\left(\Delta P V_{t}^{I D}\right) \mathbf{1}_{t}^{h} \mathbf{1}_{t}^{p} \\
& +\gamma^{h} \text { DemandQuote }{ }_{t}^{\text {Dahd }} \mathbf{1}_{t}^{h}+\epsilon^{h} \operatorname{Volume}_{t}^{I D} \mathbf{1}_{t}^{h}+\beta_{h} \sqrt{\Delta t} \\
\left(\Delta P_{t}^{I D}\right)^{l} & =c^{l}+\alpha_{1}^{l} \Delta P_{t-1}^{I D} \mathbf{1}_{t}^{l}+\alpha_{2}^{l} \Delta P_{t-2}^{I D} \mathbf{1}_{t}^{l}+\alpha_{3}^{l} \Delta P_{t-3}^{I D} \mathbf{1}_{t}^{l} \\
& +k_{w}^{l n}\left(\Delta W i n d_{t}^{I D}\right) \mathbf{1}_{t}^{l} \mathbf{1}_{t}^{n}+k_{w}^{l p}\left(\Delta W i n d_{t}^{I D}\right) \mathbf{1}_{t}^{l} \mathbf{1}_{t}^{p} \\
& +k_{P V}^{l n}\left(\Delta P V_{t}^{I D}\right) \mathbf{1}_{t}^{l} \mathbf{1}_{t}^{n}+k_{P V}^{l p}\left(\Delta P V_{t}^{I D}\right) \mathbf{1}_{t}^{l} \mathbf{1}_{t}^{p} \\
& +\gamma^{l} \text { DemandQuote } e_{t}^{\text {Dahd }} \mathbf{1}_{t}^{l}+\epsilon^{l} \operatorname{Volume}_{t}^{I D} \mathbf{1}_{t}^{l}+\beta_{l} \sqrt{\Delta t}
\end{aligned}
$$

The examination of autocorrelation function of price changes for a certain quarter of an hour shows that the first 3 lags of price changes should be selected in the autoregressive part of the model. Changes in the wind, $\Delta W i n d_{t}^{I D}$, and in the PV, $\Delta P V_{t}^{I D}$, are real time updated forecasts, available at the time when the bids are placed. ${ }^{8}$ Volume $_{t}^{I D}$ is the volume trade at the time when the price change is observed. The bids for a certain quarter of an hour do not occur at equal time intervals in the continuous bidding. In fact, market participants start bidding around $4 \mathrm{pm}$, after the day-ahead prices are published at EPEX and continuous trades go up to 45 minutes before the beginning of the delivery period. Thus, the time steps between consecutively placed bids are not equal, but can vary from some seconds to several hours. We take into account this time discontinuity by including in our list of explanatory variables the control variable $\sqrt{\Delta t}$.

In Tables 6 and 7 we show descriptive statistics for the price changes and

\footnotetext{
${ }^{8}$ Results are available upon request
} 
volume trades for the 15-minute continuous trading for delivery periods in different times of the day. We observe that the volatility of intraday price changes increases continuously between the morning quarter of hours (H7Q1) up to noon (H12Q4) and decreases again towards the evening (quarters of hour 18). Thus, the higher the demand, the larger the average price changes in the continuous trading. The volume of trades is on average the highest and more volatile for the first and last quarters of each one of the investigated hours, independent on the time of the day.

\section{Empirical results}

\subsection{Modeling deviations of last prices from the day-ahead price}

The model shown in Equation (7) has been estimated for the historical differences between the last prices and the day-ahead prices separately for winter and summer and we further distinguished among peak (8 am and $8 \mathrm{pm}$ ) and off-peak hours. This approach is justified by the different price levels in summer compared to the winter time and by the different demand profiles during peak and off-peak hours (see [23] for an extensive discussion on the seasonality of electricity prices).

The overall OLS estimation results for each case study are shown in Table 8. We further tested for a threshold effect in the demand quote in each case. The threshold variable is the demand quote and the threshold location is estimated using the methodology described in section 4.2. All model parameters in Equations (7) are allowed to vary among regimes. We found evidence for significant threshold effect only in the case of winter peak case study. Results are available in Table 9.

Throughout all variables are significant and show the expected sign (see Table 8). Dummy variables which explain the jigsaw pattern are statistically significant and their inclusion still allows significant marginal effects of fundamental variables on delta prices. The coefficients of positive/negative forecasting errors in wind and PV are significant at $1 \%$ significance level. Positive forecasting errors of wind/PV signal market participants more capacity available in the market than planned. This will have a decreasing effect on the residual demand and will further decrease last price bids. Viceversa, when updated forecasts signal less infeed from renewables than planned in the day ahead (negative forecasting errors), market participants will increase their bid prices intraday accordingly. 
At the time of the last price bids, market participants do not know yet the real control area balances, but forecasts of those are used in practice. This is reflected in the coefficients of balances forecasts which are statistically significant in all case studies and have a positive sign. Higher control area balances are a signal of excess demand which has not been yet balanced out in the intraday market, and this will be reflected in higher intraday last prices.

We observe that the coefficient of demand quote is negative during the offpeak regimes, but it turns into positive during peak hours. In both summer and winter regimes, the mean value of demand quote in the off-peak hours is slightly below one, touching a maximum of 1.291 and 1.178, respectively (as shown in Tables 4 and 5). Thus, on average, the traditional capacity planned in the market covers the expected demand for the day-ahead. However, higher levels of demand quote (up to a maximum observed in off-peak of about 1.2), power producers plan less capacity for the day ahead, due to a higher expectation of renewables infeed in the market. It is known that in the night hours extreme wind infeed has been empirically observed (see [23]). The input from renewable energies is expected to be, on average, $20 \%$ of the total input production mix in Germany (see [22]). Renewables will be fed with priority into the grid, decreasing the residual demand. This will imply further that price bids in the intraday market will be in the less convex area of the merit order curve, thus market participants will bid lower prices intraday. This assumption is confirmed by the negative sign of the coefficients of demand quote in the off-peak hours winter/summer, as shown in Table 8.

In summer peak, descriptive statistics show that on average, the demand quote exceeds 1.2. Thus, power producers plan less capacity in the market, given the volatile infeed from photovoltaic in peak hours. However, demand quotes above 1.2 reflect the situation where the $20 \%$ expected infeed from renewables will not suffice and there will be still high residual demand in the market. This will have an increasing effect on intraday prices in general and on the last prices in particular, which is confirmed by the positive sign of the coefficient of demand quote. This is reflected in the high maximum spreads between the last prices and day-ahead prices observed in summer peak, as shown in Table 5.

We found no significant threshold effect in the demand quote in summerrelated case studies and in winter off-peak. This shows that in those seasons, market participants adjust linearly last prices (and implicitly the spreads last prices-day-ahead prices) to market fundamentals. However, in winter 
peak time we found evidence for asymmetric behavior (see Table 9). Thus, a threshold in the demand quote was found significant at the level of 1.058. In the regime of low levels of demand quote (regime $1,<1.058$ ), we observe that coefficients are generally not statistically significant. That is, power producers have low expectation of renewable infeed in the day-ahead, and in consequence plan sufficient traditional capacity to satisfy expected demand. However, when demand levels are high, thus in regime 2, delta prices adjust linearly to forecasting errors in renewable energy, to control area balances and to demand quote. An increase in demand quote in this regime will suppress bid prices in the intraday market, since again higher demand quote levels reflect a high expectation of infeed from renewable energies, which will lower the price level. The coefficient of control area balances is positive and significant. This reflects two situations: if there is high infeed from renewables in the market, negative forecasts of control area balances will suppress the intraday last prices. By contrary, in the presence of high demand quote not fully covered by renewables infeed, positive forecasts in control area balances will increase intraday price bids.

The model can be used to forecast the last prices submitted for a certain quarter of one hour intraday. This is based on a rigourous forecasting model for the control area balances. This model is highly relevant for practitioners: the main goal of market participants is to clear their positions in the dayahead and intraday markets and avoid participating in the more expensive balancing market.

\subsection{Model for the continuous trades for quarter-hourly products}

We estimated the model specification shown in Equation (8) for each one of the following delivery periods: hour 7 (quarters 1-4), hour 12 (quarters 1-4) and hour 18 (quarters 1-4). We aim at analysing whether the impact of fundamentals on the bidding behavior depends on the time of the day. Thus, we analyse representative delivery periods within one day: morning, noon peak and (for winter evening) peak. In Tables 10, 13 and 15 we show the overall estimation without threshold of the model shown in Equation (8) applied to data sorted for hours 7, 12 and 18, respectively, quarters $1-4$. In the lower panel of the tables we show a benchmark, where we estimated the model without fundamental variables. We further tested for threshold effect in the demand quote in all case studies and found significant threshold effect as shown in Tables 11 and 12 for the four quarters of hour 7, and in Tables 14 
and 16 for each quarter of hours 12 and 18, respectively. The threshold values are significant, accordingly to the likelihood ratio test, as discussed in section 4.1. The graphs and calculations corresponding to each threshold values are available upon request. We have tested for threshold significance also in the other fundamental variables, but no conclusive results were obtained.

By comparing the values of the $R^{2}$ between the lower and upper panels in Tables 10, 13 and 15, we observe that in the model where market fundamentals are considered, the $R^{2} \mathrm{~s}$ increases. The increase becomes more obvious for the quarters of hour 12, where market fundamentals help increasing the explanatory power of the model by up to 4 times.

By examining Tables 10 and 13 we observe that during morning (quarters 1-4 hour 7) and evening (quarters 1-4 hour 18), market participants adjust their intraday bids to lagged price changes, which replace the role of fundamental variables. Thus, during morning and evening updated forecasts of wind and photovoltaic become less relevant. However, the coefficients of fundamental variables become significant during noon (see Table 13). This can be due to the fact that over noon there is a high demand for electricity in the market and in the same time it is more difficult to optimally plan capacity, given the highly volatile infeed from photovoltaic and wind. Thus, the effect of market fundamentals increases with an increased expected share from renewable energy. In this context, updated forecasts in wind and PV available at the time of the bid become highly relevant information for market participants who adjust their bids accordingly. Negative forecasting errors in wind and PV will increase intraday prices, while positive forecasting errors in renewables will have a suppressing effect on prices.

In particular, by examining the threshold model applied to price changes for quarters 1-4 of hour 12 we can conclude an asymmetric adjustment to forecasting errors in renewables (see Table 14). In both quarters 1 and 2 the coefficients of wind forecasting errors (positive/negative) are not significant in regime 1 (of low demand quote), but they turn significant in regime 2 . Similarly, in the fourth quarter of hour 12 the coefficient of negative forecasting errors of wind and of positive forecasting errors of PV are significant only in the second regime of the demand quote. These situations justify the choice of demand quote as threshold variable: in the high regime of the demand quote, thus, when there is excess demand uncovered by the planned traditional capacity in the market, forecasting errors of renewables influence the bidding behavior in the intraday market. Interestingly, for quarter 3 of hour 12 we observe however a higher speed of adjustment of price changes to 
forecasting errors from renewables in the lower demand quote regime than in regime 2. However, this can be due to the fact that less than $10 \%$ of the overall observations are concentrated in regime 1.

As already mentioned, the results of the threshold model applied to observations in hours 7 and 18 (Tables 11 and 16) show that the role of forecasting errors of renewables for the morning and eyeing quarters drops. Still, positive forecasting errors in PV will decrease prices in quarter 4 of hour 7 in regime 2, which reflects the ramping up effect of the sun. By contrary, during quarters 1-3 of hour 18, negative forecasting errors of wind will increase price changes intraday in the same high regime of the demand quote. In addition, negative forecasting errors of $\mathrm{PV}$ increase intraday prices in the first quarter of hour 18. After this quarter, however, the role of forecasting errors of PV drops, showing the ramping down effect of the sun.

We observe that the coefficient of volume of trades is significant only for quarter 4 of hour 7 (see Table 10) and has a negative sign. This pattern is again observed in the threshold model for hour 7 (see Table 11). When we allow for threshold effect in the demand quote, the coefficient of volume trades for quarter 4 of hour 7 is significant and has a negative sign in regime 1 , when the demand quote is below 1.415 (see Tables 11). The observations in regime 1 are further split into two regimes, as shown in Table 12, where a second threshold has been found significant when the demand quote is at 1.178. In the low regime, with demand quote below 1.178 , we observe again that the coefficient of volume of trades is statistically significant and has a negative sign. For the last quarter of hour 7 the intraday price is below the average price bid for hour 7 in the day ahead due to the sun ramping up effect. This becomes apparent in the jigsaw pattern shown in Figures 3 and 4. Thus, the volume of trades in quarter 4 of hour 7 corresponds to the supply side market participants who need to lower their conventional output, due to an excess of infeed from PV. This has a suppressing effect on the intraday prices. By contrary, the coefficient of volume trades becomes positive and significant in quarter 2 of hour 7 in the second sample split for this case study (see Table 12). Thus, when the demand quote exceeds 1.145, demand side volume of trades will further increase intraday prices.

The same pattern of coefficients of volume of trades holds also for the results concerning quarters $1-4$ for hour 12 . The coefficient is significant and has a positive sign for the first quarter and turns into negative in quarter 4 in the overall OLS estimation and in the upper regime of the demand quote, as shown in Tables 13 and 14, respectively. However, for hour 18 this effect is 
reverted. As shown in Tables 15 and 16, the coefficient of volume of trades is significant and has a negative sign for the first quarter of hour 18 and turns into positive in the last quarter. This reflects the sun ramping down effect, which causes the jigsaw pattern for the evening hours: the intraday price for quarter 1 is below the average price bid in the day ahead for the respective hours and it ends above it for quarter 4 (as shown in Figures 3 and 4). Thus, in quarter 1 there is an excess of capacity and supply side volume of trades will lower intraday prices. The opposite will happen for the last quarter of evening hours.

\section{Conclusion}

In this study, we investigate the bidding behavior in the intraday electricity market, in the context of a fundamental model. In particular, we shed light on the impact of the updates in the forecasting errors of wind and photovoltaic (PV) on the 15-minute electricity price changes in the continuous bidding. We employ a unique data set of the latest forecasts of wind and PV available to traders prior to the placements of their price bids intraday. To our knowledge, this is the first study in the literature which models intraday prices based on prior information on fundamentals. We further control for the demand/supply disequilibria, volume of trades, forecasts of control area balances and model the typical jigsaw seasonality pattern of 15-minute prices.

Our analysis is twofold. We firstly propose a forecasting model for the changes between last prices bid intraday for a certain quarter of one hour and the corresponding day-ahead price for that hour. This is highly relevant, since market participants are mainly interested in squeezing their positions in the day-ahead or intraday markets and avoid to need the control area balancing market. Secondly, a fundamental model for the price changes in the continuous bidding is derived. We found clear evidence that the bidding behavior is influenced by forecasting errors in renewables, available at the time of the bid. In particular, intraday prices increase in negative forecasting errors, while positive forecasting errors have a suppressing effect on prices.

We account for both linear and asymmetric adjustments of price changes of market fundamentals. The asymmetries are driven by the threshold variable demand-quote. The location of the threshold show market participants the proportion in which the expected demand is covered by the planned 
traditional capacity in the day-ahead market. Dependent whether the market is in the lower/upper regime of the demand-quote, market participants can intuitively form expectations about the expected infeed from renewable energies, wind and PV, in the market and adjust their bids accordingly. Our model desentangles the effect of market fundamentals dependent on the regime of the demand quote and further dependent of the time of the day. Tangentially, market fundamentals influence more the bidding behavior in the middle of the day than during mornings and evenings. There is an asymmetric adjustment of electricity prices with respect to both volume of trades and forecasting errors in renewables. Namely, in the high regime of the demand quote, where there is too little planned traditional capacity in the day-ahead market, market participants incorporate the information of the latest available forecasting errors of renewables in their bids. This effect is more obvious for the mid-day quarters, but less obvious during morning and evening hours.

The identification of regimes in the demand quote helps also to desentangle the demand/supply side volume of trades. In the regime of high demand quote, demand-side volume of trades have an increasing effect on prices. Vice versa, supply-side volumes have a suppressing effect on intraday prices, which becomes obvious in the low regime of the demand quote.

\section{Aknowledgements}

The authors thank Hendrik Brockmeyer and Claus Liebenberger for their valuable input in the data collection step. We further thank Karl Frauendorfer and Reik Börger for very useful discussions about the intraday markets. We also thank Jonas Adam for technical support with this paper. 


\section{References}

[1] Karakatsani, N., Bunn, D., 2008. Intra-day and regime-switching dynamics in electricity price formation. Energy Economics, 30 1776-1797.

[2] Cludius, J., Hermann, H., Matthes, F., Graichen, V., 2014. The merit order effect of wind and photovoltaic electricity generation in germany 20082016: Estimation and distributional implications. Energy Economics 44, 302313.

[3] E., Garnier, R., Madlener, 2014. Balancing forecast errors in continuous-trade intraday markets. FCN WP 2/2014, RWTH Aachen University School of Business and Economics.

[4] Gianfreda, A., 2010. Volatility and volume effects in european electricity spot markets. Econ. Notes 39 (1), 4763.

[5] Grabber, D., 2014. Handel mit Strom aus erneuerbaren Energien. Springer Gabler.

[6] Graeber, D., Kleine, A., 2013. The combination of forecasts in the trading of electricity from renewable energy sources. J Bus Econ 83, 409435.

[17] Hadsell, L., Marathe, A., 2006. A tarch examination of the return volatilityvolume relationship in electricity futures. Appl. Financ. Econ. 16 (12), 893901.

[8] Hagemann, S., 2013. Price Determinants in the German Intraday Market for Electricity: An Empirical Analysis - Working Paper, Essen.

[9] Hagemann, S., Weber, C., 2013. An Empirical Analysis of Liquidity and its Determinants in The German Intraday Market for Electricity - Working Paper, Essen.

[10] Hansen, B., 1996. Inference when a nuisance parameter is not identified under the null hypothesis, Econometrica. 
[11] Hansen, B., 2000. Sample splitting and threshold estimation, Econometrica, 68.

[12] Hansen, B. \& Seo, B., 2000. Testing for threshold cointegration in vector error correction models, Working Paper.

[13] Just, S., Weber, C., 2012. Strategic behavior in the german balancing energy mechanism: Incentives, evidence, costs and solutions, eWL Working Paper.

[14] Jø'nsson, T., Pinson, P., Madsen, H., 2010. On the market impact of wind energy forecasts. Energy Economics 32 (2), 313-320.

[15] Ketterer, J., 2014. The impact of wind power generation on the electricity price in germany. Energy Economics 44, 270280.

[16] Klaeboe, G., Eriksrud, A.L., Fleten, S.-E., 2013. Benchmarking time series based forecasting models for electricity balancing market prices. RPF Working Paper No. 2013-006.

[17] Hadsell, L., Marathe, A., 2006. A tarch examination of the return volatilityvolume relationship in electricity futures. Appl. Financ. Econ. 16 (12), 893901.

[18] Mller, C., Rachev, S., Fabozzi, F., 2011. Balancing energy strategies in electricity portfolio management. Energy Economics 22 (1), 2-11.

[19] Nicolosi, M., Fürsch, M., 2009. The impact of an increasing share of res-e on the conventional power market the example of germany. Z. Energiewirtschaft 3,246254 .

[20] Nicolosi, M., 2010. Wind power generation and power system flexibility - An empirical analysis of extreme events in Germany under the new negative price regime, Energy Policy 38 (11), 7257-7268. . 
617

618

619

[21] Paraschiv, F., 2013. Adjustment policy of deposit rates in the case of Swiss non-maturing savings accounts. Journal of Applied Finance \& Banking, 3(2), $271-323$.

[22] Paraschiv, F., Erni, D. \& Pietsch, R., 2014. The impact of renewable energies on EEX day-ahead electricity prices. Energy Policy, 73, 196-210.

[23] Paraschiv, F., Fleten, S.-E. \& Schürle, M., 2015. A spot-forward model for electricity prices with regime shifts. Energy Economics, 47, 142-153. 


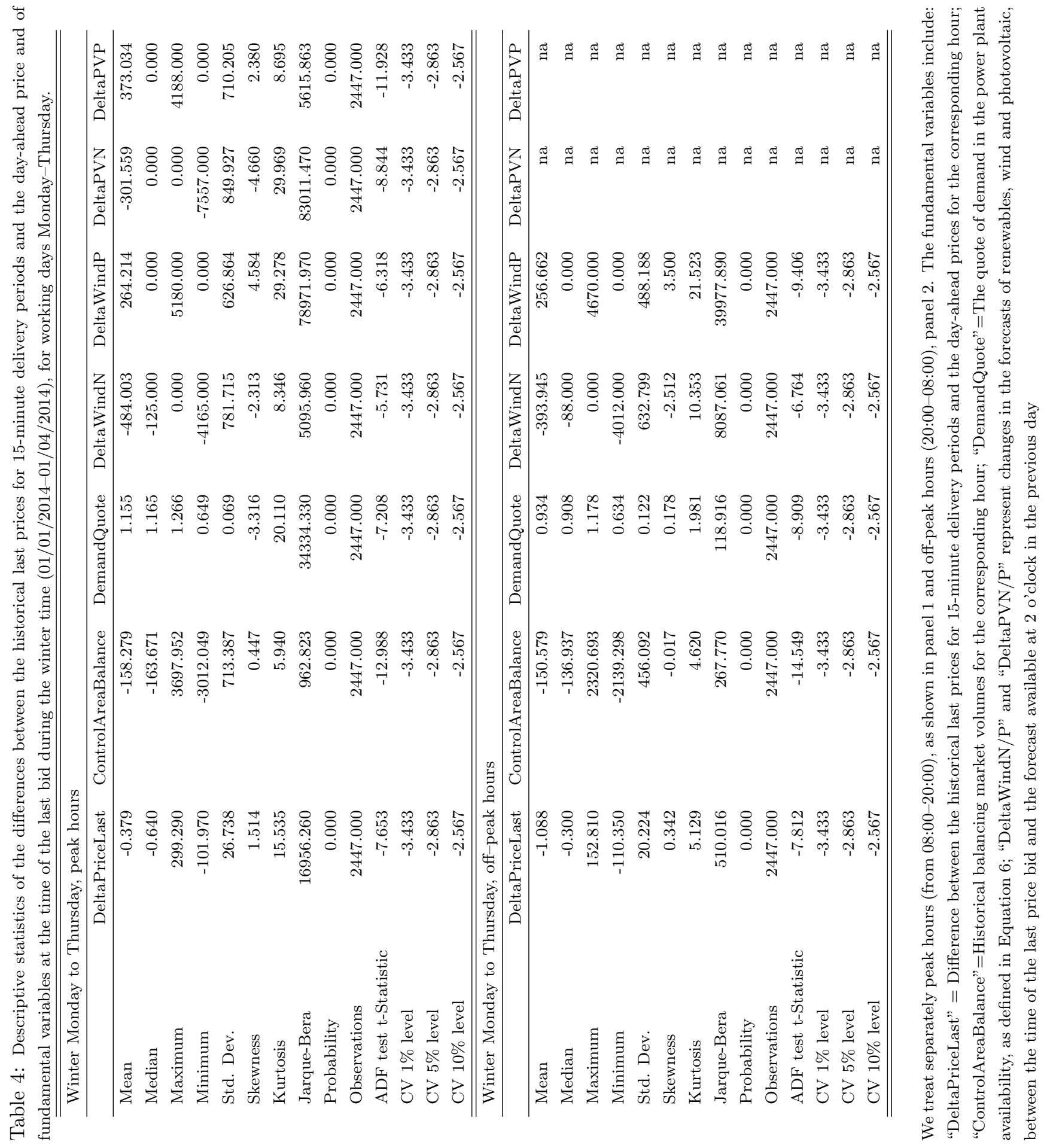




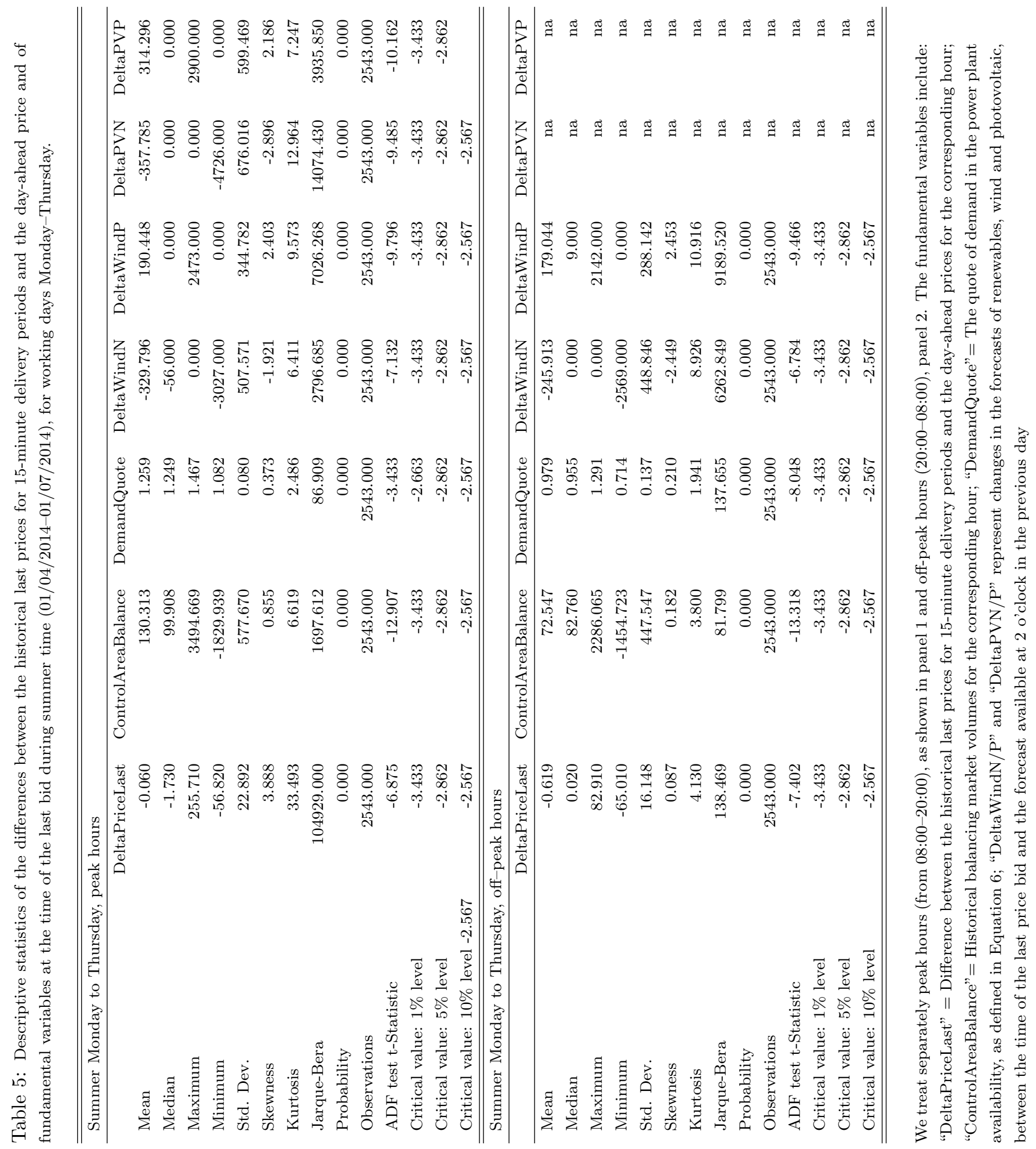




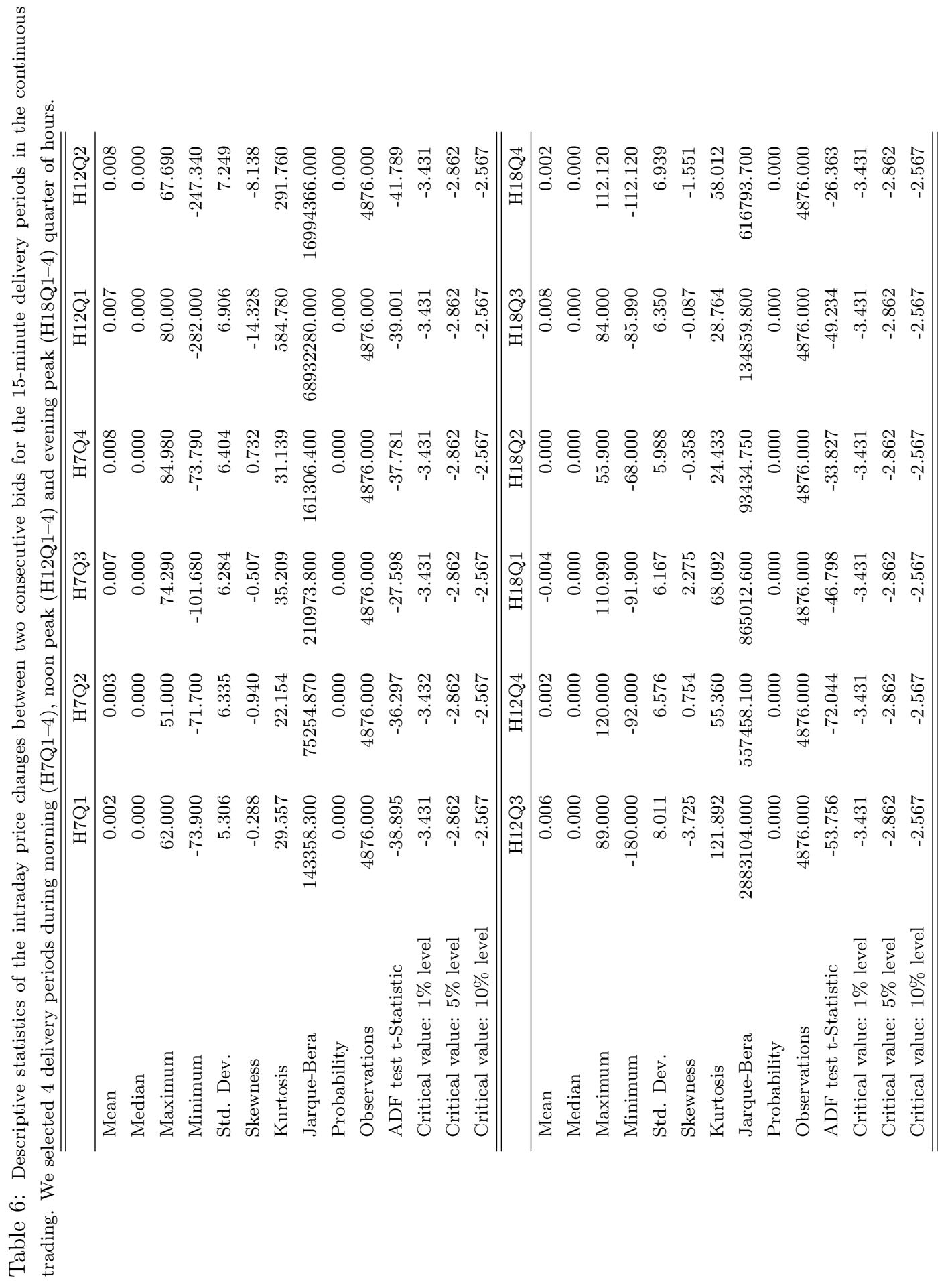




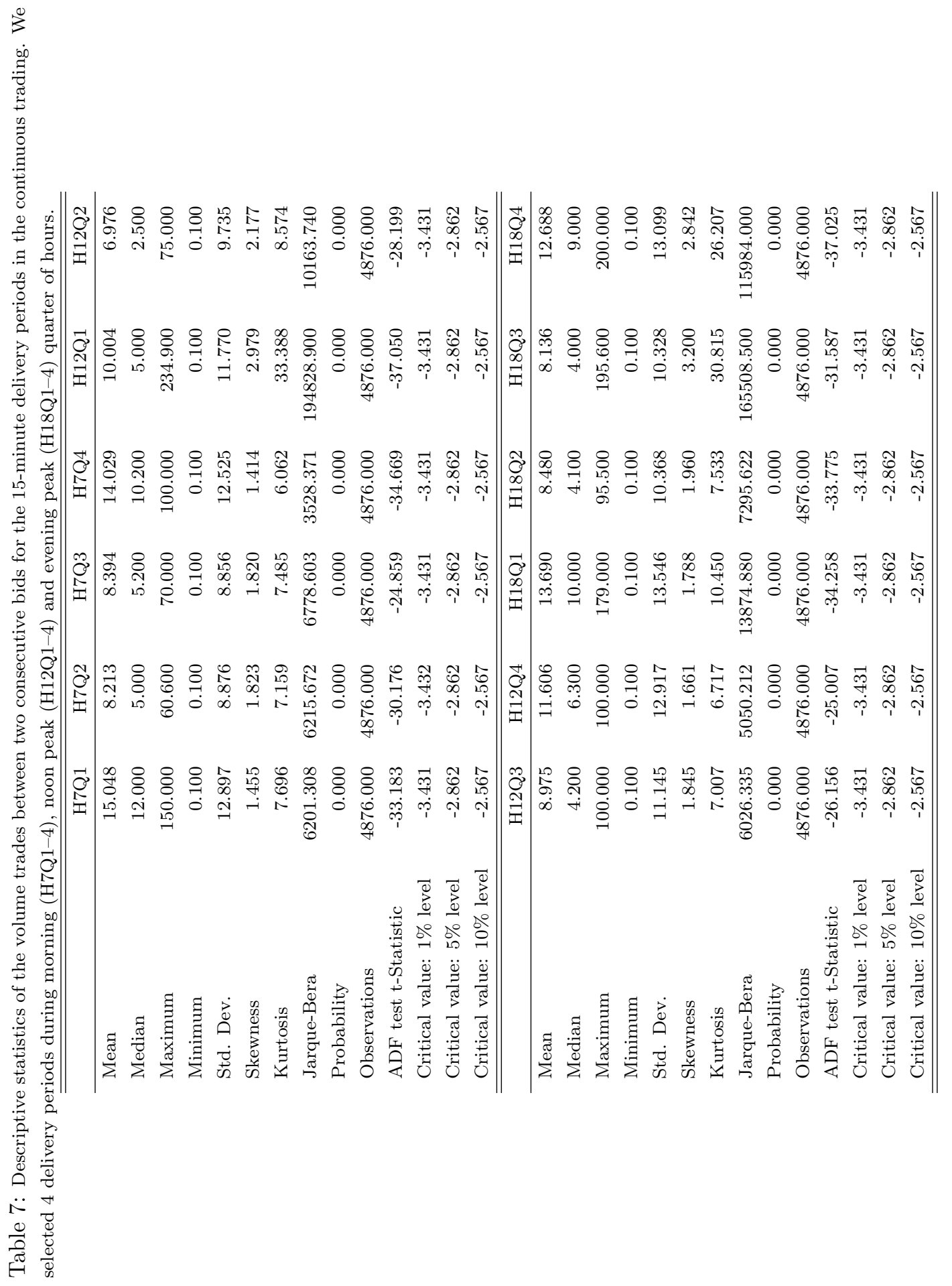


Table 8: Estimation results of the model shown in Equation 7. Global OLS without threshold

\begin{tabular}{|c|c|c|c|c|c|c|c|c|}
\hline \multicolumn{9}{|c|}{ Dependent variable Delta Last Price- Price DayAhedd } \\
\hline & \multicolumn{2}{|c|}{ Summer off-peak } & \multicolumn{2}{|c|}{ Summer peak } & \multicolumn{2}{|c|}{ Winter off-peak } & \multicolumn{2}{|c|}{ "Winter peak } \\
\hline & Coeff & Std. err. & Coeff & Std. err. & Coeff & Std. err. & Coeff & Std. err. \\
\hline Co & $7.388^{*}$ & $(1.971)$ & $-20.956^{*}$ & $(6.128)$ & $14.469^{*}$ & $(4.762)$ & -9.015 & $(10.354)$ \\
\hline DemandQ & $-7.438^{*}$ & $(2.159)$ & $10.929^{* *}$ & $(4.852)$ & $-12.715^{*}$ & $(4.605)$ & -0.354 & $(8.728)$ \\
\hline Balancing & $0.007^{*}$ & $(0.001)$ & $0.008^{*}$ & $(0.001)$ & $0.014^{*}$ & $(0.001)$ & $0.009^{*}$ & $(0.001)$ \\
\hline DeltaWindF & $\mathrm{P}-0.005^{*}$ & $(0.001)$ & $-0.002^{* *}$ & $(0.001)$ & $-0.003^{*}$ & $(0.001)$ & $-0.003^{*}$ & $(0.001)$ \\
\hline DeltaWinds & $\mathrm{N}-0.007^{*}$ & $(0.001)$ & $-0.012^{*}$ & $(0.001)$ & $-0.004^{*}$ & $(0.001)$ & $-0.004^{*}$ & $(0.001)$ \\
\hline DeltaPVP & - & - & $-0.003^{*}$ & $(0.001)$ & - & - & $-0.003^{*}$ & $(0.001)$ \\
\hline DeltaPVN & - & - & $-0.004^{*}$ & $(0.001)$ & - & - & $-0.005^{*}$ & $(0.001)$ \\
\hline DQ1M & $10.170^{*}$ & $(1.112)$ & $10.022 *$ & $(1.462)$ & $-4.561^{*}$ & $(1.729)$ & $23.808^{*}$ & $(2.340)$ \\
\hline DQ2M & $3.515^{*}$ & $(1.144)$ & 2.192 & $(1.507)$ & $-5.094^{*}$ & $(1.717)$ & $11.336^{*}$ & $(2.148)$ \\
\hline DQ3M & $-6.519^{*}$ & $(1.122)$ & -1.486 & $(1.463)$ & -3.148 & $(1.704)$ & 2.740 & $(2.207)$ \\
\hline DQ4M & $-10.454^{*}$ & (1.139) & $-6.031^{*}$ & $(1.622)$ & -1.187 & $(1.719)$ & -0.548 & $(2.296)$ \\
\hline DQ1A & $-13.845^{*}$ & (1.219) & $-8.111^{*}$ & (1.539) & 3.114 & $(1.848)$ & $-6.098^{*}$ & $(2.173)$ \\
\hline DQ2A & $-6.852^{*}$ & $(1.229)$ & 0.268 & $(1.374)$ & -0.948 & $(1.802)$ & 3.203 & $(2.016)$ \\
\hline DQ3A & 0.349 & (1.161) & $3.458^{* *}$ & $(1.341)$ & $-4.578^{* *}$ & (1.793) & $16.773^{*}$ & $(2.118)$ \\
\hline DQ4A & $4.842^{*}$ & $(1.203)$ & $13.132^{*}$ & $(1.451)$ & $-4.568^{* *}$ & $(1.825)$ & $25.588^{*}$ & $(2.294)$ \\
\hline Rsquared & \multicolumn{2}{|c|}{$35.43 \%$} & \multicolumn{2}{|c|}{$37.99 \%$} & \multicolumn{2}{|c|}{$28.76 \%$} & \multicolumn{2}{|c|}{$36.63 \%$} \\
\hline No. Obs. & \multicolumn{2}{|c|}{2543} & \multicolumn{2}{|c|}{2483} & \multicolumn{2}{|c|}{2447} & \multicolumn{2}{|c|}{2363} \\
\hline
\end{tabular}


Table 9: Winter peak, threshold estimation results. Threshold variable: Demand Quote

Threshold estimation (threshold variable DemandQ)

Dependent variable Delta Last Price- Price Dahd

\begin{tabular}{|c|c|c|c|c|}
\hline \multirow{3}{*}{$\begin{array}{l}\text { Threshold value } \\
\text { Co }\end{array}$} & \multicolumn{2}{|c|}{$\begin{array}{c}\text { Regime } \mathbf{1} \\
<=1.058\end{array}$} & \multicolumn{2}{|c|}{$\begin{array}{c}\text { Regime 2 } \\
>1.058\end{array}$} \\
\hline & Coeff & Std. Err. & Coeff & Std. Err. \\
\hline & $-48.973^{*}$ & $(15.527)$ & $63.563^{*}$ & $(22.987)$ \\
\hline DemandQ & $26.810^{* *}$ & $(12.806)$ & $-61.545^{*}$ & $(19.412)$ \\
\hline Balancing & 0.003 & $(0.002)$ & $0.010^{*}$ & $(0.001)$ \\
\hline DeltaWindP & -0.004 & $(0.003)$ & $-0.002^{* *}$ & $(0.001)$ \\
\hline DeltaWindN & $-0.006^{* *}$ & $(0.003)$ & $-0.004^{*}$ & $(0.001)$ \\
\hline DeltaPVP & -0.003 & $(0.002)$ & $-0.004^{*}$ & $(0.001)$ \\
\hline DeltaPVN & $-0.006^{*}$ & $(0.001)$ & $-0.006^{*}$ & $(0.001)$ \\
\hline DQ1M & $41.322 *$ & $(8.710)$ & $21.500 *$ & $(2.324)$ \\
\hline DQ2M & $21.880^{*}$ & $(7.985)$ & $10.443^{*}$ & $(2.129)$ \\
\hline DQ3M & 4.806 & $(7.948)$ & 3.682 & $(2.205)$ \\
\hline DQ4M & 2.266 & $(8.284)$ & 0.298 & $(2.329)$ \\
\hline DQ1A & -8.175 & $(7.420)$ & -1.367 & $(2.340)$ \\
\hline DQ2A & 8.898 & $(7.325)$ & 3.440 & $(2.207)$ \\
\hline DQ3A & $30.651^{*}$ & $(7.536)$ & $12.192^{*}$ & $(2.235)$ \\
\hline DQ4A & $45.249 *$ & $(7.616)$ & $17.453^{*}$ & $(2.369)$ \\
\hline Rsquared & \multicolumn{2}{|c|}{$48.61 \%$} & \multicolumn{2}{|c|}{$35.93 \%$} \\
\hline No. Obs. & \multicolumn{2}{|c|}{652} & \multicolumn{2}{|c|}{1711} \\
\hline
\end{tabular}

$\overline{\overline{\text { Standard errors are shown in parenthesis. }{ }^{*} \text {, and }{ }^{* *} \text { denote a test statistic is statistically significant at }}}$ the $1 \%$ and $5 \%$ level of significance, respectively. 
Table 10: Estimation results hour 7, Quarters 1-4, global OLS without threshold, entire sample

\begin{tabular}{|c|c|c|c|c|c|c|c|c|}
\hline \multicolumn{9}{|c|}{$\begin{array}{l}\text { OLS estimation of the model including fundamental variables } \\
\text { Dependent variable Delta Price }\end{array}$} \\
\hline & \multicolumn{2}{|c|}{ H7Q1 } & \multicolumn{2}{|c|}{ H7Q2 } & \multicolumn{2}{|c|}{ H7Q3 } & \multicolumn{2}{|c|}{ H7Q4 } \\
\hline & Coeff & Std. err. & Coeff & Std. err. & Coeff & Std. err. & Coeff & Std. err \\
\hline Co & 0.288 & $(0.645)$ & -0.450 & $(0.965)$ & -1.392 & $(1.139)$ & -1.102 & $(0.858)$ \\
\hline DeltaPrice1 & $-0.208^{*}$ & $(0.030)$ & $-0.320^{*}$ & $(0.032)$ & $-0.244^{*}$ & $(0.035)$ & $-0.281^{*}$ & $(0.033)$ \\
\hline DeltaPrice2 & $-0.157^{*}$ & $(0.032)$ & $-0.159^{*}$ & $(0.021)$ & $-0.121^{*}$ & $(0.027)$ & $-0.175^{*}$ & $(0.020)$ \\
\hline DeltaPrice3 & $-0.084^{*}$ & $(0.017)$ & $-0.080^{*}$ & $(0.018)$ & $-0.084^{*}$ & $(0.019)$ & $-0.086^{*}$ & $(0.016)$ \\
\hline DemandQuote & -0.300 & $(0.543)$ & 0.381 & $(0.829)$ & 0.966 & $(0.965)$ & 1.011 & $(0.736)$ \\
\hline Volume & 0.008 & $(0.005)$ & 0.015 & $(0.009)$ & 0.001 & $(0.009)$ & $-0.020^{*}$ & $(0.006)$ \\
\hline SqrTimeStep & -0.833 & $(1.420)$ & -1.212 & $(1.359)$ & $4.101^{*}$ & $(1.319)$ & $4.127^{*}$ & $(1.547)$ \\
\hline DeltaWindIntrP & P 0.0001 & $(0.0002)$ & 0.0002 & $(0.0002)$ & -0.001 & $(0.001)$ & -0.001 & $(0.001)$ \\
\hline DeltaWindIntrN & N-0.001* & $(0.0001)$ & 0.0001 & $(0.0002)$ & 0.0002 & $(0.001)$ & 0.001 & $(0.001)$ \\
\hline DeltaPVIntraP & 0.0001 & $(0.001)$ & 0.001 & $(0.001)$ & 0.0002 & $(0.001)$ & 0.002 & $(0.002)$ \\
\hline DeltaPVIntraN & 0.001 & $(0.001)$ & $0.002^{* *}$ & $(0.001)$ & -0.001 & $(0.001)$ & 0.000 & $(0.001)$ \\
\hline Rsquared & \multicolumn{2}{|c|}{$5.989 \%$} & \multicolumn{2}{|c|}{$10.930 \%$} & \multicolumn{2}{|c|}{$7.333 \%$} & \multicolumn{2}{|c|}{$9.481 \%$} \\
\hline No. Obs. & \multicolumn{2}{|c|}{6979} & \multicolumn{2}{|c|}{4873} & \multicolumn{2}{|c|}{4977} & \multicolumn{2}{|c|}{7175} \\
\hline
\end{tabular}

OLS estimation of the autoregressive model, excluding fundamental variables

Dependent variable Delta Price

\begin{tabular}{lcc|cc|cc|cc}
\hline \hline & \multicolumn{2}{c|}{ H7Q1 } & \multicolumn{2}{c|}{ H7Q2 } & \multicolumn{2}{c|}{ H7Q3 } & \multicolumn{2}{c}{ H7Q4 } \\
& Coeff & Std. err. & Coeff & Std. err. & Coeff & Std. err. & Coeff & Std. err. \\
\hline Co & 0.004 & $(0.061)$ & 0.005 & $(0.086)$ & 0.010 & $(0.086)$ & 0.007 & $(0.072)$ \\
DeltaPrice1 & $-0.207^{*}$ & $(0.012)$ & $-0.321^{*}$ & $(0.014)$ & $-0.243^{*}$ & $(0.014)$ & $-0.276^{*}$ & $(0.012)$ \\
DeltaPrice2 & $-0.158^{*}$ & $(0.012)$ & $-0.159^{*}$ & $(0.015)$ & $-0.119^{*}$ & $(0.014)$ & $-0.175^{*}$ & $(0.012)$ \\
DeltaPrice3 & $-0.083^{*}$ & $(0.012)$ & $-0.080^{*}$ & $(0.014)$ & $-0.085^{*}$ & $(0.014)$ & $-0.082^{*}$ & $(0.012)$ \\
\hline Rsquared & \multicolumn{3}{c}{$5.055 \%$} & \multicolumn{2}{c}{$9.718 \%$} & \multicolumn{2}{c}{$6.170 \%$} & \multicolumn{2}{c}{$8.085 \%$} \\
No. Obs. & \multicolumn{3}{c}{4979} & \multicolumn{2}{c}{4977} & \multicolumn{2}{c}{7175} \\
\hline
\end{tabular}

$\overline{\text { Standard errors are shown in parenthesis. }{ }^{*} \text {, and }{ }^{* *} \text { denote a test statistic is statistically significant at the }}$ $1 \%$ and $5 \%$ level of significance, respectively. The interpretation of variables is: DeltaPrice $(\mathrm{x})=$ lagged price changes 1-3; DemandQuote $=$ demand quote; Volume $=$ volume of trades; SqrTimeStep $=\sqrt{\Delta_{t}}$; DeltaWindIntrP/N=positive/negative forecasting errors in wind; DeltaPVIntraP/N=positive/negative forecasting errors in $\mathrm{PV}$. 


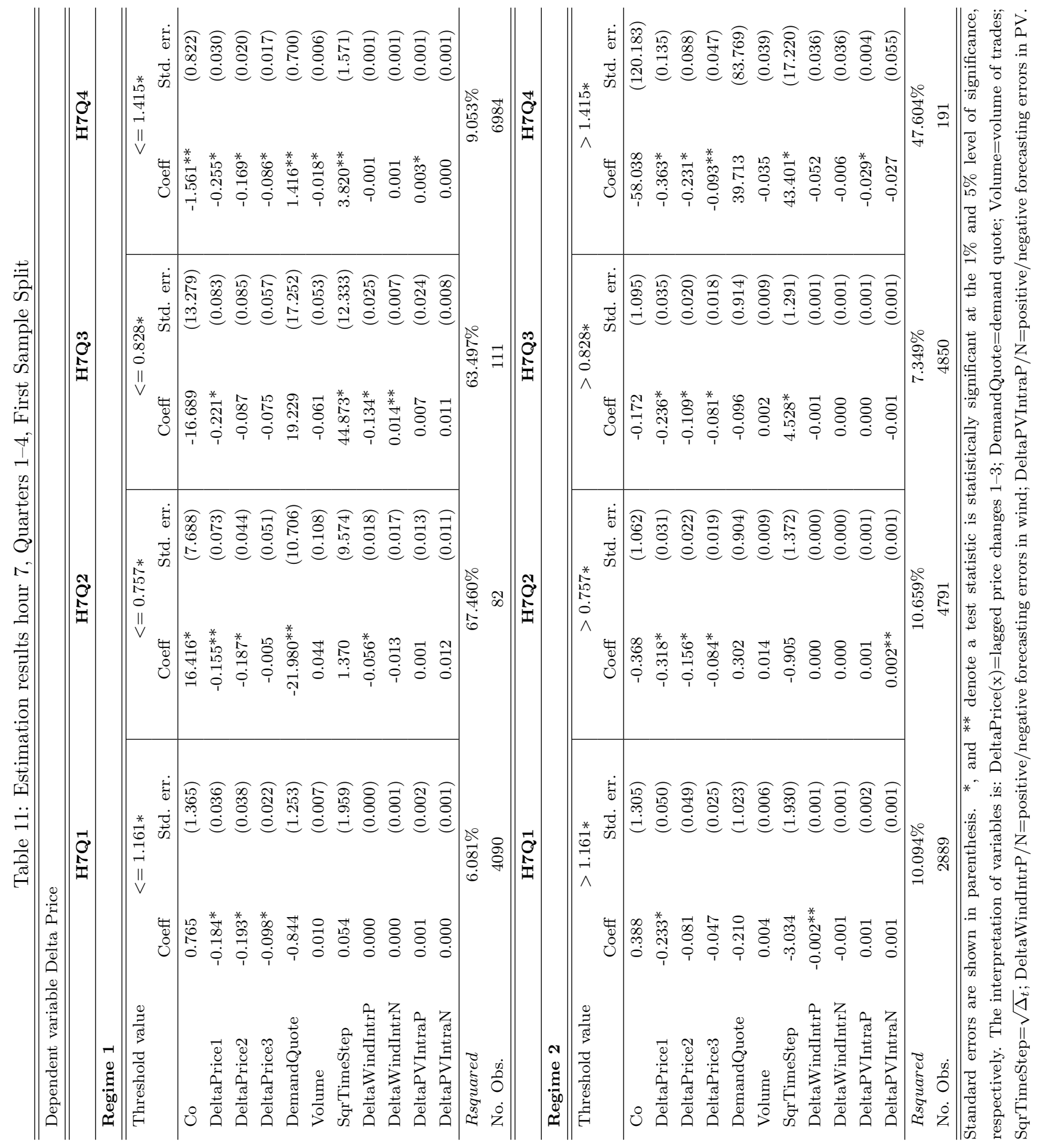


Table 12: Estimation results hour 7, Quarters 2,4, Second Sample Split. For Quarter 2 the second regime identified in the first sample split (Table 11) has been further checked for threshold effect. For Quarter 4 the observations in regime 1 (Table 11) have been further checked for threshold effect.

\begin{tabular}{|c|c|c|c|c|}
\hline \multicolumn{5}{|c|}{ Dependent variable Delta Price } \\
\hline \multicolumn{5}{|l|}{ Regime 1} \\
\hline & \multicolumn{2}{|c|}{ H7Q2 } & \multicolumn{2}{|c|}{ H7Q4 } \\
\hline \multirow[t]{2}{*}{ Threshold value } & \multicolumn{2}{|c|}{$<=1.145 *$} & \multicolumn{2}{|c|}{$<=1.178 *$} \\
\hline & Coeff & Std. err. & Coeff & Std. err. \\
\hline $\mathrm{Co}$ & -4.367 & $(3.103)$ & -2.411 & $(1.412)$ \\
\hline DeltaPrice1 & $-0.431^{*}$ & $(0.041)$ & $-0.287^{*}$ & $(0.036)$ \\
\hline DeltaPrice2 & $-0.242^{*}$ & $(0.032)$ & $-0.180^{*}$ & $(0.023)$ \\
\hline DeltaPrice3 & $-0.132 *$ & $(0.029)$ & $-0.082^{*}$ & $(0.019)$ \\
\hline DemandQuote & 4.051 & $(2.847)$ & 2.224 & $(1.284)$ \\
\hline Volume & -0.014 & $(0.013)$ & $-0.019 *$ & $(0.007)$ \\
\hline SqrTimeStep & 1.178 & $(1.807)$ & $4.501^{*}$ & $(1.694)$ \\
\hline DeltaWindIntrP & $-0.001^{*}$ & $(0.000)$ & -0.001 & $(0.001)$ \\
\hline DeltaWindIntrN & -0.001 & $(0.001)$ & 0.000 & $(0.001)$ \\
\hline DeltaPVIntraP & 0.000 & $(0.002)$ & -0.001 & $(0.001)$ \\
\hline DeltaPVIntraN & 0.001 & $(0.001)$ & 0.002 & $(0.002)$ \\
\hline Rsquared & \multicolumn{2}{|c|}{$18.171 \%$} & \multicolumn{2}{|c|}{$9.526 \%$} \\
\hline No. Obs. & \multicolumn{2}{|c|}{2175} & \multicolumn{2}{|c|}{4605} \\
\hline \multicolumn{5}{|l|}{ Regime 2} \\
\hline & \multicolumn{2}{|c|}{ H7Q2 } & \multicolumn{2}{|c|}{ H7Q4 } \\
\hline \multirow[t]{2}{*}{ Threshold value } & \multicolumn{2}{|c|}{$>1.145 *$} & \multicolumn{2}{|c|}{$>1.178 *$} \\
\hline & Coeff & Std. err. & Coeff & Std. err. \\
\hline $\mathrm{Co}$ & -0.826 & $(2.130)$ & 3.845 & $(4.117)$ \\
\hline DeltaPrice1 & $-0.227^{*}$ & $(0.045)$ & $-0.168^{*}$ & $(0.042)$ \\
\hline DeltaPrice2 & $-0.102^{*}$ & $(0.029)$ & $-0.091^{*}$ & $(0.028)$ \\
\hline DeltaPrice3 & $-0.058^{* *}$ & $(0.023)$ & -0.090 & $(0.047)$ \\
\hline DemandQuote & 0.536 & $(1.724)$ & -3.034 & $(3.344)$ \\
\hline Volume & $0.043^{*}$ & $(0.012)$ & -0.013 & $(0.011)$ \\
\hline SqrTimeStep & -2.138 & $(1.950)$ & 1.134 & $(3.719)$ \\
\hline DeltaWindIntrP & 0.000 & $(0.001)$ & $-0.002^{* *}$ & $(0.001)$ \\
\hline DeltaWindIntrN & 0.000 & $(0.001)$ & 0.001 & $(0.003)$ \\
\hline DeltaPVIntraP & 0.001 & $(0.001)$ & 0.006 & $(0.004)$ \\
\hline DeltaPVIntraN & $0.003^{*}$ & $(0.001)$ & $-0.005^{*}$ & $(0.001)$ \\
\hline Rsquared & \multicolumn{2}{|c|}{$7.361 \%$} & \multicolumn{2}{|c|}{$19.427 \%$} \\
\hline No. Obs. & \multicolumn{2}{|c|}{2576} & \multicolumn{2}{|c|}{1665} \\
\hline \multicolumn{5}{|c|}{$\begin{array}{l}\text { Standard errors are shown in parenthesis. }{ }^{*}, \text { and }{ }^{* *} \text { denote a test statistic is statistically significant at the } \\
1 \% \text { and } 5 \% \text { level of significance, respectively. The interpretation of variables is: DeltaPrice }(\mathrm{x})=\text { lagged price } \\
\text { changes } 1-3 \text {; DemandQuote=demand quote; Volume }=\text { volume of trades; SqrTimeStep }=\sqrt{\Delta_{t}} \text {; DeltaWind- } \\
\text { IntrP } / \mathrm{N}=\text { positive/negative forecasting errors in wind; DeltaPVIntraP } / \mathrm{N}=\text { positive } / \text { negative forecasting } \\
\text { errors in PV. }\end{array}$} \\
\hline
\end{tabular}


Table 13: Estimation results hour 12, Quarters 1-4, global OLS without threshold

\begin{tabular}{|c|c|c|c|c|c|c|c|c|}
\hline \multicolumn{9}{|c|}{$\begin{array}{l}\text { OLS estimation of the model incl } \\
\text { Dependent variable Delta Price }\end{array}$} \\
\hline & \multicolumn{2}{|c|}{ H12Q1 } & \multicolumn{2}{|c|}{ H12Q2 } & \multicolumn{2}{|c|}{ H12Q3 } & \multicolumn{2}{|c|}{ H12Q4 } \\
\hline & Coeff & Std. err. & Coeff & Std. err. & Coeff & Std. err. & Coeff & Std. err. \\
\hline Co & -0.558 & $(0.672)$ & -0.674 & $(0.977)$ & -0.111 & $(0.765)$ & -0.032 & $(0.799)$ \\
\hline DeltaPrice1 & $-0.175^{* *}$ & $(0.086)$ & $-0.167^{*}$ & $(0.043)$ & $-0.207^{*}$ & $(0.038)$ & $-0.140^{*}$ & $(0.020)$ \\
\hline DeltaPrice2 & $-0.071^{* *}$ & $(0.032)$ & -0.040 & $(0.023)$ & $-0.077^{* *}$ & $(0.036)$ & $-0.079^{*}$ & $(0.020)$ \\
\hline DeltaPrice3 & -0.102 & $(0.060)$ & -0.018 & $(0.017)$ & -0.039 & $(0.021)$ & -0.020 & $(0.013)$ \\
\hline DemandQuote & 0.109 & $(0.499)$ & 0.408 & $(0.755)$ & 0.156 & $(0.578)$ & 0.088 & $(0.635)$ \\
\hline Volume & $0.053^{*}$ & $(0.019)$ & 0.012 & $(0.009)$ & -0.012 & $(0.009)$ & $-0.013^{* *}$ & $(0.006)$ \\
\hline SqrTimeStep & 0.423 & $(1.570)$ & 1.868 & $(1.365)$ & 1.010 & $(1.348)$ & 1.683 & $(1.853)$ \\
\hline DeltaWindIntrP & $-0.001^{*}$ & $(0.000)$ & -0.001 & $(0.001)$ & $-0.001^{*}$ & $(0.000)$ & $-0.001^{*}$ & $(0.000)$ \\
\hline DeltaWindIntrN & $-0.001^{*}$ & $(0.000)$ & -0.001 & $(0.001)$ & -0.001 & $(0.001)$ & $-0.002^{* *}$ & $(0.001)$ \\
\hline DeltaPVIntraP & $-0.002 * *$ & $(0.001)$ & $-0.002 * *$ & $(0.001)$ & $-0.002^{* *}$ & $(0.001)$ & $-0.004^{*}$ & $(0.001)$ \\
\hline DeltaPVIntraN & 0.000 & $(0.001)$ & -0.001 & $(0.001)$ & $-0.002^{* *}$ & $(0.001)$ & $-0.002^{* *}$ & $(0.001)$ \\
\hline Rsquared & \multicolumn{2}{|c|}{$7.296 \%$} & \multicolumn{2}{|c|}{$4.705 \%$} & \multicolumn{2}{|c|}{$7.011 \%$} & \multicolumn{2}{|c|}{$8.411 \%$} \\
\hline No. Obs. & \multicolumn{2}{|c|}{6859} & \multicolumn{2}{|c|}{5449} & \multicolumn{2}{|c|}{6558} & \multicolumn{2}{|c|}{7931} \\
\hline
\end{tabular}

OLS estimation of the autoregressive model excluding fundamental variables

Dependent variable Delta Price

\begin{tabular}{|c|c|c|c|c|c|c|c|c|}
\hline & \multicolumn{2}{|c|}{ H12Q1 } & \multicolumn{2}{|c|}{ H12Q2 } & \multicolumn{2}{|c|}{ H12Q3 } & \multicolumn{2}{|c|}{ H12Q4 } \\
\hline & Coeff & Std. err. & Coeff & Std. err. & Coeff & Std. err. & Coeff & Std. err \\
\hline $\mathrm{Co}$ & 0.006 & $(0.077)$ & 0.004 & $(0.099)$ & 0.005 & $(0.092)$ & 0.003 & $(0.066)$ \\
\hline DeltaPrice1 & $-0.172^{*}$ & $(0.012)$ & $-0.167^{*}$ & $(0.014)$ & $-0.206^{*}$ & $(0.012)$ & $-0.137^{*}$ & $(0.011)$ \\
\hline DeltaPrice2 & $-0.065^{*}$ & $(0.012)$ & $-0.041^{*}$ & $(0.014)$ & $-0.077^{*}$ & $(0.013)$ & $-0.078^{*}$ & $(0.011)$ \\
\hline DeltaPrice3 & $-0.099^{*}$ & $(0.012)$ & -0.018 & $(0.014)$ & $-0.041^{*}$ & $(0.012)$ & -0.019 & $(0.011)$ \\
\hline Rsquared & \multicolumn{2}{|c|}{$3.715 \%$} & \multicolumn{2}{|c|}{$2.733 \%$} & \multicolumn{2}{|c|}{$4.219 \%$} & \multicolumn{2}{|c|}{$2.187 \%$} \\
\hline No. Obs. & \multicolumn{2}{|c|}{6859} & \multicolumn{2}{|c|}{5449} & \multicolumn{2}{|c|}{6558} & \multicolumn{2}{|c|}{7931} \\
\hline
\end{tabular}

$\overline{\text { Standard errors are shown in parenthesis. }{ }^{*} \text {, and }{ }^{* *} \text { denote a test statistic is statistically significant at the }}$ $1 \%$ and $5 \%$ level of significance, respectively. The interpretation of variables is: DeltaPrice $(\mathrm{x})=$ lagged price changes 1-3; DemandQuote $=$ demand quote; Volume $=$ volume of trades; SqrTimeStep $=\sqrt{\Delta_{t}}$; DeltaWind$\operatorname{IntrP} / \mathrm{N}=$ positive/negative forecasting errors in wind; DeltaPVIntraP $/ \mathrm{N}=$ positive/negative forecasting errors in PV. 
Table 14: Estimation results hour 12, Quarters 1-4, First Sample Split

\begin{tabular}{|c|c|c|c|c|c|c|c|c|}
\hline \multicolumn{9}{|c|}{ Dependent variable Delta Price } \\
\hline \multicolumn{9}{|l|}{ Regime 1} \\
\hline & \multicolumn{2}{|c|}{ H12Q1 } & \multicolumn{2}{|c|}{ H12Q2 } & \multicolumn{2}{|c|}{ H12Q3 } & \multicolumn{2}{|c|}{ H12Q4 } \\
\hline \multirow[t]{2}{*}{ Threshold value } & \multicolumn{2}{|c|}{$<=1.245 *$} & \multicolumn{2}{|c|}{$<=1.245 *$} & \multicolumn{2}{|c|}{$<=1.146 *$} & \multicolumn{2}{|c|}{$<=1.197 *$} \\
\hline & Coeff & Std. err. & Coeff & Std. err. & Coeff & Std. err. & Coeff & Std. err. \\
\hline Co & -0.669 & $(1.982)$ & -0.693 & $(3.302)$ & 0.421 & $(2.418)$ & 0.365 & (3.418) \\
\hline DeltaPrice1 & -0.202 & $(0.118)$ & $-0.126^{*}$ & $(0.043)$ & $-0.191^{* *}$ & $(0.075)$ & $-0.108^{*}$ & $(0.031)$ \\
\hline DeltaPrice2 & -0.065 & $(0.043)$ & $-0.042^{* *}$ & $(0.021)$ & -0.142 & $(0.085)$ & $-0.082^{* *}$ & $(0.040)$ \\
\hline DeltaPrice3 & -0.099 & $(0.078)$ & -0.010 & $(0.018)$ & -0.023 & $(0.078)$ & -0.030 & $(0.017)$ \\
\hline DemandQuote & 0.163 & $(1.685)$ & 0.518 & $(2.798)$ & 0.036 & $(2.104)$ & -0.378 & $(3.069)$ \\
\hline Volume & $0.070^{* *}$ & $(0.028)$ & 0.022 & $(0.012)$ & -0.007 & $(0.029)$ & 0.003 & $(0.016)$ \\
\hline SqrTimeStep & -1.363 & $(2.119)$ & -0.205 & $(1.886)$ & -9.905 & $(5.560)$ & 0.880 & $(2.436)$ \\
\hline DeltaWindIntrP & 0.000 & $(0.001)$ & 0.000 & $(0.001)$ & $0.005^{*}$ & $(0.002)$ & -0.001 & $(0.001)$ \\
\hline DeltaWindIntrN & J -0.001 & $(0.001)$ & -0.001 & $(0.001)$ & $-0.006^{*}$ & $(0.001)$ & 0.002 & $(0.002)$ \\
\hline DeltaPVIntraP & $-0.003^{*}$ & $(0.001)$ & $-0.003^{*}$ & $(0.001)$ & $-0.007^{* *}$ & $(0.003)$ & -0.002 & $(0.002)$ \\
\hline DeltaPVIntraN & 0.001 & $(0.001)$ & -0.001 & $(0.001)$ & -0.002 & $(0.002)$ & $-0.003^{*}$ & $(0.001)$ \\
\hline Rsquared & \multicolumn{2}{|c|}{$9.155 \%$} & \multicolumn{2}{|c|}{$3.806 \%$} & \multicolumn{2}{|c|}{$27.371 \%$} & \multicolumn{2}{|c|}{$7.764 \%$} \\
\hline No. Obs. & \multicolumn{2}{|c|}{3911} & & & \multicolumn{2}{|c|}{487} & \multicolumn{2}{|c|}{2438} \\
\hline \multicolumn{9}{|l|}{ Regime 2} \\
\hline & \multicolumn{2}{|c|}{ H12Q1 } & \multicolumn{2}{|c|}{ H12Q2 } & \multicolumn{2}{|c|}{ H12Q3 } & \multicolumn{2}{|c|}{ H12Q4 } \\
\hline \multirow[t]{2}{*}{ Threshold value } & \multicolumn{2}{|c|}{$>1.245 *$} & \multicolumn{2}{|c|}{$>0.757 *$} & \multicolumn{2}{|c|}{$>1.146 *$} & $>1$ & $197 *$ \\
\hline & Coeff & Std. err. & Coeff & Std. err. & Coeff & Std. err. & Coeff & Std. err \\
\hline $\mathrm{Co}$ & 0.125 & $(1.349)$ & -1.036 & $(1.809)$ & -0.037 & $(0.928)$ & 0.405 & $(0.944)$ \\
\hline DeltaPrice1 & $-0.094^{* *}$ & $(0.040)$ & $-0.256^{*}$ & $(0.060)$ & $-0.208^{*}$ & $(0.040)$ & $-0.155^{*}$ & $(0.022)$ \\
\hline DeltaPrice2 & -0.108 & $(0.040)$ & -0.046 & $(0.053)$ & -0.072 & $(0.038)$ & -0.075 & $(0.020)$ \\
\hline DeltaPrice3 & $-0.099 * *$ & $(0.043)$ & -0.035 & $(0.035)$ & -0.039 & $(0.022)$ & -0.011 & $(0.018)$ \\
\hline DemandQuote & -0.216 & $(0.965)$ & 0.630 & $(1.304)$ & 0.065 & $(0.693)$ & -0.163 & $(0.692)$ \\
\hline Volume & $0.018^{* *}$ & $(0.008)$ & -0.006 & $(0.013)$ & -0.012 & $(0.010)$ & $-0.021^{*}$ & $(0.006)$ \\
\hline SqrTimeStep & 1.140 & $(1.439)$ & $3.942^{* *}$ & $(1.758)$ & 2.263 & $(1.191)$ & -0.097 & $(1.700)$ \\
\hline DeltaWindIntrP & $-0.002^{*}$ & $(0.000)$ & $-0.002^{* *}$ & $(0.001)$ & $-0.001^{*}$ & $(0.000)$ & -0.001 & $(0.001)$ \\
\hline DeltaWindIntrN & J $-0.001 *$ & $(0.000)$ & $-0.002^{* *}$ & $(0.001)$ & -0.001 & $(0.001)$ & $-0.002^{* *}$ & $(0.001)$ \\
\hline DeltaPVIntraP & 0.000 & $(0.001)$ & -0.001 & $(0.001)$ & $-0.002^{* *}$ & $(0.001)$ & $-0.002^{* *}$ & $(0.001)$ \\
\hline DeltaPVIntraN & -0.001 & $(0.001)$ & $-0.002^{* *}$ & $(0.001)$ & -0.001 & $(0.001)$ & $-0.004^{*}$ & $(0.001)$ \\
\hline Rsquared & & $68 \%$ & 10. & $60 \%$ & & $0 \%$ & 11 & $24 \%$ \\
\hline No. Obs. & & 948 & & & & & & 93 \\
\hline
\end{tabular}

$\overline{\text { Standard errors are shown in parenthesis. }{ }^{*}, \text { and }{ }^{* *} \text { denote a test statistic is statistically significant at the }}$ $1 \%$ and $5 \%$ level of significance, respectively. The interpretation of variables is: DeltaPrice $(\mathrm{x})=$ lagged price changes 1-3; DemandQuote $=$ demand quote; Volume $=$ volume of trades; SqrTimeStep $=\sqrt{\Delta_{t}}$; DeltaWindIntrP $/ \mathrm{N}=$ positive/negative forecasting errors in wind; DeltaPVIntraP/N=positive/negative forecasting errors in PV. 
Table 15: Estimation results hour 18, Quarters 1-4, global OLS without threshold

\begin{tabular}{|c|c|c|c|c|c|c|c|c|}
\hline \multicolumn{9}{|c|}{$\begin{array}{l}\text { OLS estimation of the model incl } \\
\text { Dependent variable Delta Price }\end{array}$} \\
\hline & \multicolumn{2}{|c|}{ H18Q1 } & \multicolumn{2}{|c|}{ H18Q2 } & \multicolumn{2}{|c|}{ H18Q3 } & \multicolumn{2}{|c|}{ H18Q4 } \\
\hline & Coeff & Std. err. & Coeff & Std. err. & Coeff & Std. err. & Coeff & Std. err \\
\hline $\mathrm{Co}$ & -0.156 & $(0.809)$ & 0.068 & $(0.941)$ & -1.861 & $(0.980)$ & -1.160 & (1.087) \\
\hline DeltaPrice1 & $-0.206^{*}$ & $(0.032)$ & $-0.276^{*}$ & $(0.036)$ & $-0.254^{*}$ & $(0.033)$ & $-0.214^{*}$ & $(0.036)$ \\
\hline DeltaPrice2 & $-0.163^{*}$ & $(0.033)$ & $-0.149^{*}$ & $(0.025)$ & $-0.173^{*}$ & $(0.030)$ & $-0.105^{*}$ & $(0.023)$ \\
\hline DeltaPrice3 & $-0.131^{*}$ & $(0.024)$ & $-0.090^{*}$ & $(0.024)$ & $-0.101^{*}$ & $(0.020)$ & $-0.149 *$ & $(0.045)$ \\
\hline DemandQuote & 0.324 & $(0.642)$ & 0.186 & $(0.772)$ & 1.274 & $(0.806)$ & 0.708 & $(0.908)$ \\
\hline Volume & $-0.025^{*}$ & $(0.004)$ & $-0.028^{*}$ & $(0.006)$ & $0.041^{*}$ & $(0.007)$ & $0.037^{*}$ & $(0.005)$ \\
\hline SqrTimeStep & 0.143 & $(1.319)$ & -1.628 & $(1.062)$ & -0.233 & $(0.921)$ & $-3.565^{*}$ & $(1.258)$ \\
\hline DeltaWindIntrP & 0.000 & $(0.000)$ & 0.000 & $(0.000)$ & $-0.001^{*}$ & $(0.000)$ & 0.000 & $(0.000)$ \\
\hline DeltaWindIntrN & $-0.003^{*}$ & $(0.001)$ & -0.001 & $(0.001)$ & -0.001 & $(0.001)$ & -0.001 & $(0.001)$ \\
\hline DeltaPVIntraP & 0.011 & $(0.009)$ & -0.006 & $(0.013)$ & -0.004 & $(0.011)$ & -0.055 & $(0.033)$ \\
\hline DeltaPVIntraN & $-0.014^{* *}$ & $(0.007)$ & 0.004 & $(0.011)$ & -0.012 & $(0.027)$ & 0.087 & $(0.105)$ \\
\hline Rsquared & \multicolumn{2}{|c|}{$11.135 \%$} & \multicolumn{2}{|c|}{$8.929 \%$} & \multicolumn{2}{|c|}{$8.048 \%$} & \multicolumn{2}{|c|}{$7.037 \%$} \\
\hline No. Obs. & \multicolumn{2}{|c|}{8507} & \multicolumn{2}{|c|}{5982} & \multicolumn{2}{|c|}{6162} & \multicolumn{2}{|c|}{8936} \\
\hline
\end{tabular}

OLS estimation of the autoregressive model excluding fundamental variables

Dependent variable Delta Price

\begin{tabular}{|c|c|c|c|c|c|c|c|c|}
\hline & \multicolumn{2}{|c|}{ H18Q1 } & \multicolumn{2}{|c|}{ H18Q2 } & \multicolumn{2}{|c|}{ H18Q3 } & \multicolumn{2}{|c|}{ H18Q4 } \\
\hline & Coeff & Std. err. & Coeff & Std. err. & Coeff & Std. err. & Coeff & Std. err \\
\hline Co & -0.005 & $(0.058)$ & -0.001 & $(0.073)$ & 0.005 & $(0.082)$ & 0.005 & $(0.078)$ \\
\hline DeltaPrice1 & $-0.201^{*}$ & $(0.011)$ & $-0.276^{*}$ & $(0.013)$ & $-0.252^{*}$ & $(0.013)$ & $-0.207^{*}$ & $(0.010)$ \\
\hline DeltaPrice2 & $-0.163^{*}$ & $(0.011)$ & $-0.146^{*}$ & $(0.013)$ & $-0.170^{*}$ & $(0.013)$ & $-0.100 *$ & $(0.011)$ \\
\hline DeltaPrice3 & $-0.131^{*}$ & $(0.011)$ & $-0.088^{*}$ & $(0.013)$ & $-0.098^{*}$ & $(0.013)$ & $-0.144^{*}$ & $(0.010)$ \\
\hline Rsquared & \multicolumn{2}{|c|}{$6.099 \%$} & \multicolumn{2}{|c|}{$7.715 \%$} & \multicolumn{2}{|c|}{$7.247 \%$} & \multicolumn{2}{|c|}{$5.859 \%$} \\
\hline No. Obs. & \multicolumn{2}{|c|}{8507} & \multicolumn{2}{|c|}{5982} & \multicolumn{2}{|c|}{6162} & \multicolumn{2}{|c|}{8936} \\
\hline
\end{tabular}

$\overline{\text { Standard errors are shown in parenthesis. }{ }^{*} \text {, and }{ }^{* *} \text { denote a test statistic is statistically significant at the }}$ $1 \%$ and $5 \%$ level of significance, respectively. The interpretation of variables is: DeltaPrice $(\mathrm{x})=$ lagged price changes 1-3; DemandQuote $=$ demand quote; Volume $=$ volume of trades; SqrTimeStep $=\sqrt{\Delta_{t}}$; DeltaWind$\operatorname{IntrP} / \mathrm{N}=$ positive/negative forecasting errors in wind; DeltaPVIntraP $/ \mathrm{N}=$ positive/negative forecasting errors in PV. 
Table 16: Estimation results hour 18, Quarters 1-4, First Sample Split

\begin{tabular}{|c|c|c|c|c|c|c|c|c|}
\hline \multicolumn{9}{|c|}{ Dependent variable Delta Price } \\
\hline \multicolumn{9}{|l|}{ Regime 1} \\
\hline & \multicolumn{2}{|c|}{ H18Q1 } & \multicolumn{2}{|c|}{ H18Q2 } & \multicolumn{2}{|c|}{ H18Q3 } & \multicolumn{2}{|c|}{ H18Q4 } \\
\hline \multirow[t]{2}{*}{ Threshold value } & \multicolumn{2}{|c|}{$<=0.915 *$} & \multicolumn{2}{|c|}{$<=1.221 *$} & \multicolumn{2}{|c|}{$<=1.219 *$} & \multicolumn{2}{|c|}{$<=1.442 *$} \\
\hline & Coeff & Std. err. & Coeff & Std. err. & Coeff & Std. err. & Coeff & Std. err. \\
\hline $\mathrm{Co}$ & 46.694 & $(152.240)$ & 0.020 & $(2.024)$ & $-5.932 *$ & $(2.012)$ & -0.481 & $(1.031)$ \\
\hline DeltaPrice1 & $-0.510^{*}$ & $(0.116)$ & $-0.258^{*}$ & $(0.035)$ & $-0.252^{*}$ & $(0.032)$ & $-0.198^{*}$ & $(0.037)$ \\
\hline DeltaPrice2 & $-0.284^{*}$ & $(0.105)$ & $-0.197^{*}$ & $(0.030)$ & $-0.154^{*}$ & $(0.028)$ & $-0.088^{*}$ & $(0.022)$ \\
\hline DeltaPrice3 & -0.137 & $(0.086)$ & $-0.079 * *$ & $(0.031)$ & $-0.111^{*}$ & $(0.029)$ & $-0.148^{*}$ & $(0.049)$ \\
\hline DemandQuote & -52.391 & $(170.802)$ & 0.296 & $(1.758)$ & $4.995^{*}$ & $(1.757)$ & 0.142 & $(0.855)$ \\
\hline Volume & -0.051 & $(0.085)$ & $-0.038^{*}$ & $(0.008)$ & $0.041^{*}$ & $(0.008)$ & $0.035^{*}$ & $(0.005)$ \\
\hline SqrTimeStep & 6.124 & $(19.295)$ & -1.137 & $(1.179)$ & -0.772 & $(1.032)$ & $-3.303^{*}$ & $(1.266)$ \\
\hline DeltaWindIntrP & 0.019 & $(0.026)$ & 0.000 & $(0.000)$ & $-0.001^{*}$ & $(0.000)$ & 0.000 & $(0.000)$ \\
\hline DeltaWindIntrN & J -0.027 & $(0.020)$ & -0.001 & $(0.001)$ & 0.000 & $(0.000)$ & -0.001 & $(0.001)$ \\
\hline DeltaPVIntraP & -0.340 & $(0.224)$ & 0.038 & $(0.052)$ & -0.006 & $(0.014)$ & -0.053 & $(0.032)$ \\
\hline DeltaPVIntraN & 0.159 & $(0.321)$ & 0.024 & $(0.029)$ & -0.036 & $(0.045)$ & 0.086 & $(0.106)$ \\
\hline Rsquared & \multicolumn{2}{|c|}{$30.618 \%$} & \multicolumn{2}{|c|}{$8.668 \%$} & \multicolumn{2}{|c|}{$8.109 \%$} & \multicolumn{2}{|c|}{$6.356 \%$} \\
\hline No. Obs. & \multicolumn{2}{|c|}{133} & & 71 & \multicolumn{2}{|c|}{3553} & \multicolumn{2}{|c|}{8776} \\
\hline \multicolumn{9}{|l|}{ Regime 2} \\
\hline & \multicolumn{2}{|c|}{ H18Q1 } & \multicolumn{2}{|c|}{ H18Q2 } & \multicolumn{2}{|c|}{ H18Q3 } & \multicolumn{2}{|c|}{ H18Q4 } \\
\hline \multirow[t]{2}{*}{ Threshold value } & \multicolumn{2}{|c|}{$>0.915 *$} & \multicolumn{2}{|c|}{$>1.221 *$} & \multicolumn{2}{|c|}{$>1.219 *$} & & $\overline{442} *$ \\
\hline & Coeff & Std. err. & Coeff & Std. err. & Coeff & Std. err. & Coeff & Std. err. \\
\hline $\mathrm{Co}$ & 0.460 & $(0.670)$ & 0.944 & $(2.590)$ & -1.882 & $(3.752)$ & -10.224 & $(43.509)$ \\
\hline DeltaPrice1 & $-0.181^{*}$ & $(0.025)$ & $-0.284^{*}$ & $(0.064)$ & $-0.247^{*}$ & $(0.061)$ & 0.008 & $(1.892)$ \\
\hline DeltaPrice2 & $-0.161^{*}$ & $(0.035)$ & $-0.095^{*}$ & $(0.039)$ & $-0.171^{*}$ & $(0.055)$ & -0.090 & $(0.990)$ \\
\hline DeltaPrice3 & $-0.119^{*}$ & $(0.023)$ & $-0.098^{*}$ & $(0.035)$ & $-0.106^{*}$ & $(0.029)$ & -0.011 & $(0.992)$ \\
\hline DemandQuote & -0.165 & $(0.526)$ & -0.568 & $(1.970)$ & 1.163 & $(2.876)$ & -39.818 & $(57.807)$ \\
\hline Volume & $-0.025^{*}$ & $(0.004)$ & -0.008 & $(0.012)$ & $0.042^{*}$ & $(0.014)$ & 0.156 & $(0.506)$ \\
\hline SqrTimeStep & -0.212 & (1.319) & -3.076 & $(1.815)$ & 0.507 & $(1.533)$ & -48.774 & $(122.258)$ \\
\hline DeltaWindIntrP & 0.000 & $(0.000)$ & -0.001 & $(0.001)$ & 0.000 & $(0.001)$ & 0.000 & $(0.043)$ \\
\hline DeltaWindIntrN & $\mathrm{J}-0.003^{*}$ & $(0.001)$ & $-0.002^{* *}$ & $(0.001)$ & $-0.002^{*}$ & $(0.000)$ & 0.204 & $(0.301)$ \\
\hline DeltaPVIntraP & 0.012 & $(0.009)$ & -0.010 & $(0.015)$ & -0.019 & $(0.014)$ & 0.332 & $(7.980)$ \\
\hline DeltaPVIntraN & $-0.014^{* *}$ & $(0.007)$ & -0.008 & $(0.013)$ & 0.005 & $(0.031)$ & -2.765 & $(8.155)$ \\
\hline Rsquared & & $.003 \%$ & 11 & $52 \%$ & & $5 \%$ & & $24 \%$ \\
\hline No. Obs. & & 8299 & & 11 & & 97 & & 60 \\
\hline $\begin{array}{l}\text { Standard errors ar } \\
1 \% \text { and } 5 \% \text { level of } \\
\text { changes } 1-3 ; \text { Dem } \\
\text { IntrP } / \mathrm{N}=\text { positive } \\
\text { arrors in } \mathrm{PV}\end{array}$ & $\begin{array}{l}\text { re shown } \\
\text { f significal } \\
\text { landQuote } \\
\text { / negative }\end{array}$ & $\begin{array}{l}\text { arenthesis. } \\
\text { respective } \\
\text { demand qu } \\
\text { recasting e }\end{array}$ & $\begin{array}{l}\text { ind }{ }^{* *} \text { den } \\
\text { Che interpr }\end{array}$ & $\begin{array}{l}\text { te a test } \mathrm{st} \\
\text { tation of } \mathrm{v} \\
\text { lume of } \mathrm{tr}\end{array}$ & $\begin{array}{l}\text { istic is st } \\
\text { lables is: } \\
\text { es; SqrT }\end{array}$ & $\begin{array}{l}\text { tistically } \\
\text { eltaPrice }\end{array}$ & $\begin{array}{l}\text { nificant } \\
=\text { lagged } \\
{ }_{t} ; \text { Delta }\end{array}$ & $\begin{array}{l}\text { the } \\
\text { rice } \\
\text { ind- } \\
\text { ting }\end{array}$ \\
\hline
\end{tabular}

